\title{
El capital de la movilidad urbana cotidiana: motilidad en la periferia de Lima Metropolitana
}

\author{
The capital of everyday urban mobility: Motility on the periphery of Metropolitan Lima
}

\author{
Gerardo D. Regalado-Regalado \\ Universidad Nacional Mayor de San Marcos, Lima (Perú)
}

Regalado, G. D. (2019). El capital de la movilidad urbana cotidiana: motilidad en la periferia de Lima Metropolitana. Revista de Arquitectura (Bogotá), 22(I). 67-8I. https://doi.org/10.14718/ RevArq.2020.3038

\section{Resumen}

Los procesos de movilidad urbana en las ciudades latinoamericanas se enfrentan a un territorio fragmentado, desigual, no inclusivo, que altera y fragmenta las condiciones espaciotemporales en las cuales se construye la espacialidad urbana de la vida cotidiana, $y$, por ende, afecta sus desplazamientos. Es por eso por lo que se hace necesario estudiar las prácticas sociales de viajes y la relación directa de estas con el capital de motilidad que ostenta un individuo, y que le permite ejercer su habitus ambulante. En la zona periférica de Tahuantinsuyo, en la ciudad de Lima (Perú), se aplicó un método etnográfico, de tipo microetnografía-particularista, combinando observación no participante y entrevistas semiestructuradas, lo que permitió la recolección de datos cuantitativos y cualitativos para caracterizar la condición de accesibilidad, las competencias, la agencia y la apropiación, como la capacidad de autonomía para ejercer desplazamientos, con el fin de determinar el capital de motilidad. Como resultado, se determinó que este capital es alterado en función no solo de la posición socioeconómica y de la competencia con otros agentes, sino también, en relación con su grado de accesibilidad a su hábitat, sus capacidades físicas, sus habilidades o sus competencias, y se encontraron diversas y coincidentes prácticas sociales de viajes que alteran dicho capital.

Palabras clave: accesibilidad urbana; derecho a la ciudad; habitus ambulante; metropolización; producción del espacio; segregación urbana; sistemas de transporte

\begin{abstract}
The processes of urban mobility in Latin American cities face a fragmented, unequal, non-inclusive territory that alters and fragments the spatio-temporal conditions on which the urban spatiality of everyday life is built, and therefore affects its displacements. That is why it is necessary to study the social travel practices and the direct relationship with the capital of motility that an individual has and that allows him to exercise his traveling habitus. In the peripheral area of Tahuantinsuyo in the city of Lima (Peru), an ethnographic method was applied, of the micro-ethnography-particularist type, combining non-participant observation and semi-structured interviews, which allowed the collection of quantitative and qualitative data for characterize the condition of accessibility, competencies, agency and appropriation, such as the capacity for autonomy to carry out displacements, in order to determine the motility capital. As a result, it was determined that this capital is altered based not only on the socio-economic position and competition with other agents, but also, in relation to their degree of accessibility to their habitat, their physical abilities, skills or competencies, finding various and matching social travel practices that alter said capital.
\end{abstract}

Keywords: urban accessibility; right to the city; walking habitus; metropolization; space production; urban segregation; transportation systems.

\section{Introducción}

El presente artículo se deriva de los procesos investigativos para optar al grado de Doctor en Ciencias Sociales con Mención en Sociología, en la Universidad Nacional Mayor de San Marcos, Lima (Perú). Estos procesos se centran en el abordaje del fenómeno de la movilidad urbana cotidiana a partir del concepto de motilidad.

La movilidad urbana cotidiana se constituye en un mercado específico, en un campo de luchas, donde el bien codiciado es la capacidad para ejercer desplazamientos, que desarrollan los diversos tipos de agentes, a partir de principios generadores de prácticas sociales; en este caso, prácticas sociales de viajes, siguiendo la línea de Pierre Bourdieu (2012, 1999), que infiere el concepto de "habitus ambulante" (citado en García Jerez, 2016, p. 349).

Estas prácticas sociales de viajes desarrollan relaciones de dominación entre los agentes. Cada uno de ellos ostenta un "capital de motilidad". Se sigue la línea de investigación de García Jerez (2016, p. 350), quien afirma que, de acuerdo con el tamaño del capital de motilidad, este le otorga al individuo o agente, una posición en el "campo" de la movilidad urbana cotidiana, entendido este como un sistema basado en relaciones sociales jerárquicas y dominaciones entre posiciones de los agentes -individuos o grupos que desarrollan desplazamientos-, cuyas posiciones estarían definidas por la capacidad de "agencia" o actuación en dicho campo, que les otorga su capital de motilidad y les permite realizar elecciones valorativas y significativas; es decir, les confiere la "apropiación" selectiva, equitativa, democrática y colectiva de su territorio, o, en otras palabras, se apropia de su ciudad.

No obstante lo anterior, como todo capital, este puede disminuir, aumentar o desaparecer, en función de ciertas condiciones, tales como: la accesibilidad al entorno inmediato; sus competencias derivadas de sus habilidades, basadas, a su vez, en su condición física, en las adquiridas en el hogar, en la escuela o en la universidad, y 
las del tipo organizacional, fundadas en relaciones de comunidad, amicales o profesionales. Así lo infieren Kaufmann, Bergman y Joye 2004 (citados por García Jerez, 2016, p. 350).

La movilidad urbana cotidiana está condicionada, además, por un espacio urbano, que en la mayoría de las metrópolis latinoamericanas presenta un territorio fragmentado en relación con sus periferias, lo cual expresa su discontinuidad, sus inconexiones y sus segregaciones, producto, a su vez, de la ausencia o de la inequívoca planificación urbana sostenible, lo cual altera y fragmenta las condiciones espaciotemporales sobre las que se fabrica la espacialidad urbana de la vida cotidiana, y, por ende, sus desplazamientos, pero cuya población, de forma cotidiana y a partir de su capital de motilidad, ejerce una agencia que le permite apropiarse de forma selectiva de su territorio tratando de recomponer su funcionalidad en relación con el todo metropolitano (Martínez Toro, 2014) .

Esta situación lleva a formular el siguiente interrogante, que será el eje de esta investigación: ¿De qué forma la afectación de las condiciones de accesibilidad al entorno y a sus redes de movilidad, así como a las competencias o las habilidades de un individuo inmerso en un territorio fragmentado social y espacialmente, respecto al todo metropolitano, alteran su capital de motilidad disminuyendo sus posibilidades de alcanzar desplazamientos en el campo de la movilidad urbana cotidiana?

El abordaje al fenómeno de la movilidad urbana cotidiana se desarrolla a partir del concepto de motilidad, concepto que se define como "aquella capacidad real o potencial que tienen los individuos y/o grupos sociales para efectuar desplazamientos" (Kaufmann, Bergman \& Joye, 2004; Flamm \& Kaufmann, 2006).

Dicho concepto se estudiará a partir de tres dimensiones expresadas por García Jerez (2016, p. 353): 1) la accesibilidad que ofrece el medio físico-espacial, donde residen o trabajan los actores involucrados, para facilitar los desplazamientos; 2) las competencias o las habilidades que ostentan los actores o los grupos sociales para emprender desplazamientos, y que pueden ser físicas, psicológicas, tecnológicas, etc.; 3) la agencia, o capacidad de actuación en el medio o tejido urbano. Esta última dimensión permite a los involucrados una "apropiación" de sus condiciones de movilidad, por la cual tratan en su cotidianidad de reconstruir un territorio fragmentado social y espacialmente.

Las mencionadas dimensiones se correlacionan con el concepto del urbanismo fragmentador, aquella práctica, como lo mencionan Jirón y Mansilla, "que fragmenta las condiciones sobre las cuales se constituye la espacialidad urbana de la vida cotidiana" (2014, p. 1). Estas prácticas sociales exigen una relación con el tejido urbano, segmentado y atomizado, y así ocasionan discontinuidades, espacios de ganancia y de pérdida $y$, por tanto, desigualdades sociales.

\section{Metodología}

\section{El método etnográfico}

Dado que el objeto de estudio es la movilidad urbana cotidiana, se ha utilizado el método etnográfico, de tipo microetnografía-particularista; es decir, "aquel que se centra en un aspecto de la cultura o una situación social concreta". (Hernández Sampieri, Fernández Collado \& Baptista Lucio, 2014, p. 485); en este caso, las prácticas sociales de viajes.

Este método exige recolectar información a partir de la técnica de la observación no participante, empleando el levantamiento fotográfico de aquellas prácticas sociales de viajes referidas, por ejemplo, a diversos puntos de origen y destino, al uso del transporte urbano formal e informal, a los trayectos a pie o en algún vehículo no motorizado, etc.

La selección de la muestra es del tipo aleatoria, por cuanto el interés radica en explicar la naturaleza de la movilidad urbana cotidiana desde el punto de vista de su capital: la motilidad. Por lo tanto, se puede escoger a cualquier persona que se desplace por el área de estudio. La información obtenida para el presente estudio fue del tipo mixta; es decir, datos cuantitativos y cualitativos. Estos últimos son de suma importancia para medir los aspectos cualitativos de la motilidad. Además de la técnica de la observación participante, se realizaron entrevistas semiestructuradas, con preguntas cerradas y abiertas, con el fin de obtener información para medir las dimensiones de tipo cualitativo de la motilidad.

Por otro lado, el análisis de los datos cualitativos se hizo tal como señala Julio Mejía Navarrete:

El análisis de datos cualitativos, es un proceso definido en tres fases interrelacionadas: la reducción de datos que incluyen edición, categorización, codificación, clasificación y la presentación de datos; el análisis descriptivo, que permite elaborar conclusiones empíricas y descriptivas y la interpretación, que establece conclusiones teóricas y explicativas. (2011, p. 48)

Al respecto, se entrevistó a quince personas, de diferente estrato sociocultural, mediante una entrevista semiestructurada, en la que se indagó sobre las dimensiones acerca de su motilidad, a partir de sus prácticas sociales de viajes.

Para la presente investigación se ha seleccionado la II zona de Tahuantinsuyo, del distrito de Independencia (figura 1), territorio ubicado en la periferia norte de la metrópoli. Un fragmento del territorio de la Región Metropolitana de Lima, que guarda relación y conexión funcional con el cono este y el centro de la urbe, pues detenta procesos 


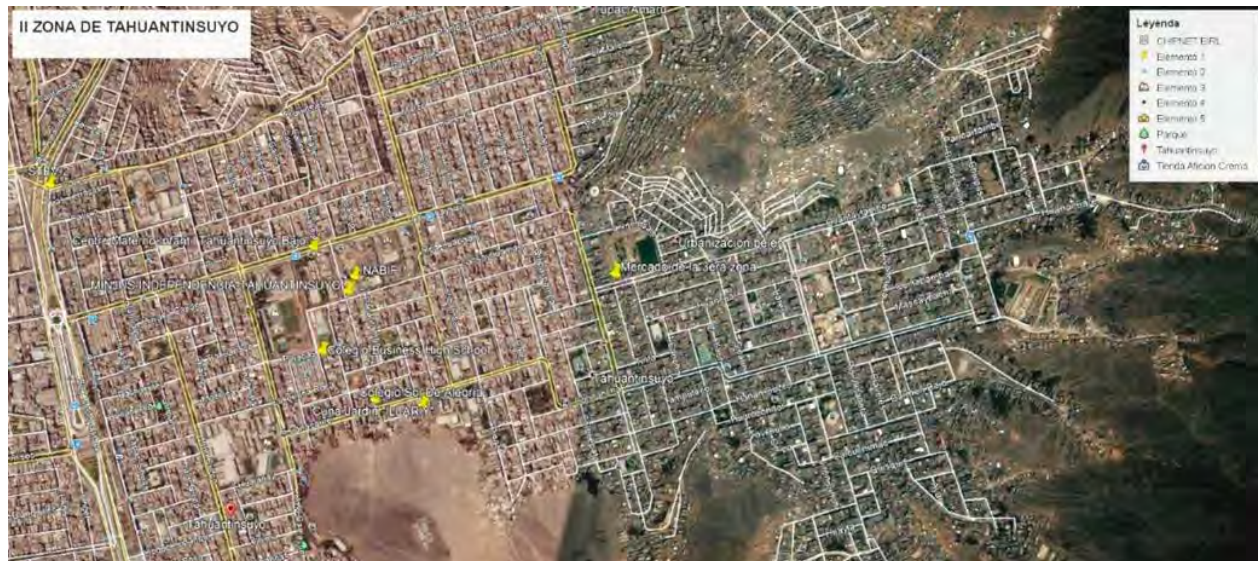

(A) Figura 1. Área de trabajo II, zona de Tahuantinsuyo, distrito de Independencia, Lima, Perú.

Fuente: Google Earth (setiembre de 2019).

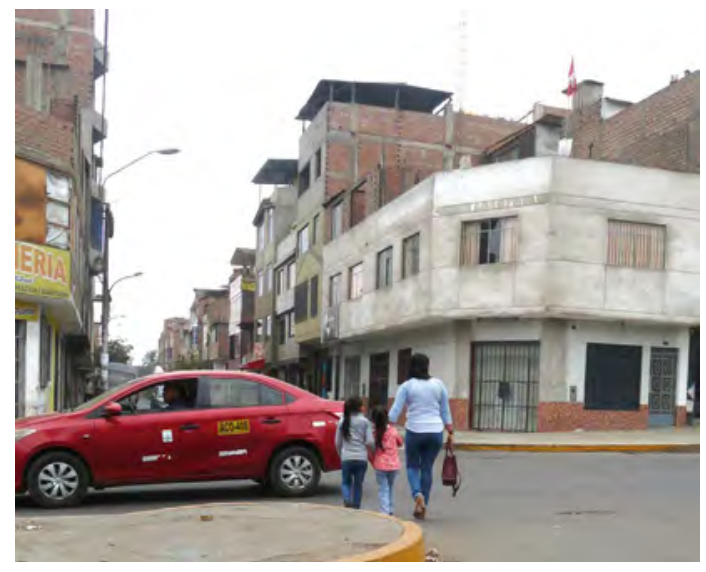

(A) Figura 2. Escenario 1: desplazamientos a pie y uso del transporte formal.

Fuente: elaboración propia (2019).

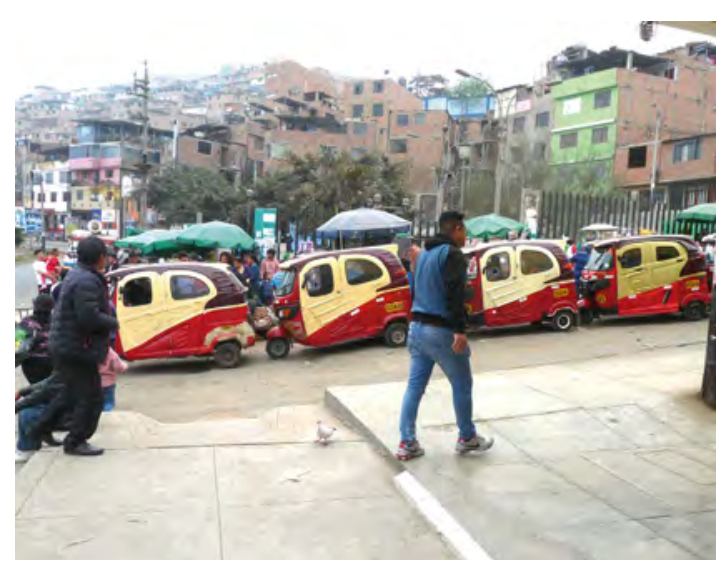

(A) Figura 3. Escenario 2: acceso a redes de movilidad informal y su relación con el mercado informal. Fuente: elaboración propia (2019).

de alta movilidad urbana cotidiana gracias a sus equipamientos metropolitanos, tales como centros comerciales, hospitales y universidades, además de tener cierto nivel de escogencia modal, por la presencia del Corredor Segregado de Alta Capacidad (COSAC), más conocido como el Metropolitano, así como de líneas de transporte urbano público denominadas alimentadoras y líneas de colectivos, taxis, combis y mototaxis; estos últimos representan el eslabón final del sistema de movilidad motorizada que hace cobertura del nivel local del distrito.

El área de trabajo presenta características socioeconómicas que acusan un nivel de heterogeneidad y un tejido social microdiferenciado, que determinan diversas prácticas sociales de viajes.

Dado que el análisis de datos cualitativos está enfocado básicamente en comprender —en este caso, a los individuos que realizan prácticas de viajes en su entorno urbano inmediato-, de forma preliminar y en el ámbito exploratorio, utilizando la técnica de recolección de información "observación no participante" a través de la

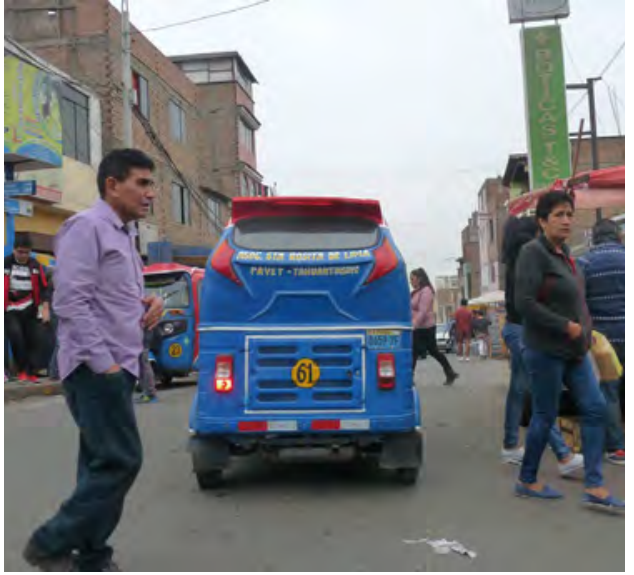

(A) Figura 4. Escenario 3: combinación de desplazamientos a pie y acceso a redes de movilidad informal.

Fuente: elaboración propia (2019).
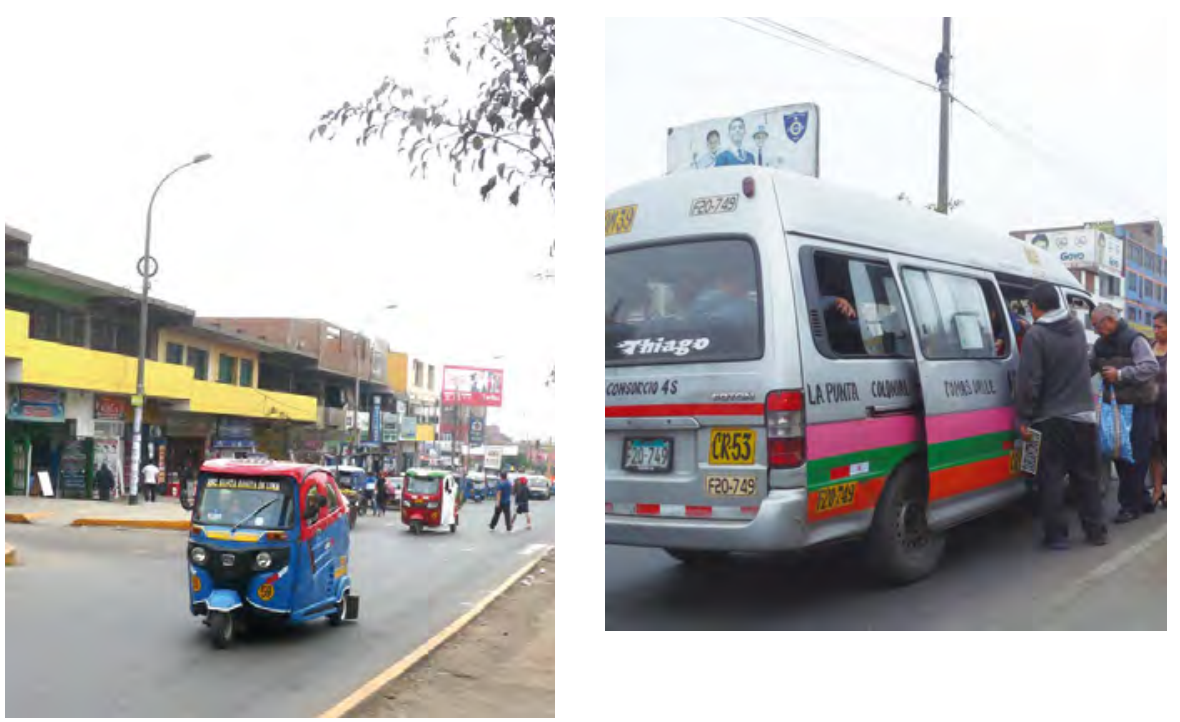

fotografía, se reconocieron algunos escenarios en relación con las diversas prácticas sociales de viajes que se desarrollan en dicha área de trabajo, tales como los desplazamientos a pie y el uso del transporte formal (figura 2), el acceso a redes de movilidad informal y su relación con el comercio informal (figura 3), la combinación de desplazamientos a pie y el acceso a redes de movilidad
(A) Figura 5. Escenario 4: el comercio informal y su relación con los desplazamientos a pie y el acceso a redes de movilidad informal.

Fuente: elaboración propia (2019) 
informal (figura4), el comercio informal y su relación con los desplazamientos a pie y el acceso a redes de movilidad informal (figura 5), el uso de las redes de movilidad informal en las vías de mayor demanda de movilidad urbana cotidiana (figura 6) y el acceso a redes de movilidad informal de mayor capacidad (figura 7).

La observación de los escenarios presentados fue de gran importancia para formular las preguntas en las entrevistas semiestructuradas, pues permitió medir las dimensiones del capital de motilidad.

Al respecto, para la medición del capital de motilidad, se establecieron dos dimensiones: 1) accesibilidad y 2) habilidades o competencias; estas últimas, por lo general de naturaleza cualitativa, a partir de los siguientes indicadores:

1. En relación con la accesibilidad:

- Trayecto cotidiano (origen y destino)

- Duración del trayecto cotidiano (hora/minutos)

- Gasto promedio por trayecto (moneda-dólares)

- Uso del transporte público

- Uso del transporte informal

- Modos de transporte motorizado usados cotidianamente

- Cambio de ruta (número de cambios/día)

- Trayectos diarios (número de viajes/día)

- Trasbordos en el desplazamiento hacia el trabajo (número de unidad de transporte/ ruta/día)

- Manejo de dispositivos tecnológicos para la movilidad (uso de dispositivo)

- Realización de trayectos a pie (recurrencia)

- Propiedad de otros modos de transporte personal (tipo de vehículo)

2. En relación con las habilidades o competencias:

- Condición física (estado de salud)

- Conocimiento del barrio

- Discapacidad y condición médica (condición física u orgánica)

- Conocimiento de las rutas de transporte

- Nivel de percepción de la seguridad de los desplazamientos (confiabilidad)

- Posesión de licencia de conductor

Para la medición de la agencia, se establecieron los siguientes indicadores:

- Grado de libertad para tomar decisiones de desplazamiento

- Grado de negociación para efectuar desplazamientos

- Nivel de asertividad para la escogencia modal

- Nivel de autoeficacia en los desplazamientos

- Grado de autonomía para efectuar desplazamientos
- Grado de control para efectuar desplazamientos

- Nivel de autodeterminación

- Nivel de pensamiento independiente

- Grado de identificación de necesidad de cambio

- Nivel de percepción de mi contexto

- Nivel de control sobre mi entorno

Para medir la apropiación, se establecieron los siguientes indicadores:

- Motivo de desplazamientos cotidianos

- Destino de desplazamientos cotidianos

- Acompañamiento de desplazamientos cotidianos

- Elección del lugar de destino

- Percepción de seguridad en el barrio

- Percepción de seguridad al desarrollar trayectos

- Interacción social en el trayecto cotidiano

Por lo anterior, la medición del capital de motilidad estará en función de la accesibilidad y de las competencias o habilidades de las que goce el poblador de la II zona de Tahuantinsuyo en el distrito de Independencia. Esto determinará un "plusvalor" otorgado, por un lado, a partir de la agencia o la capacidad de actuación en el campo de la movilidad urbana cotidiana, y, por otro, en relación con la apropiación de sus posibilidades y sus condiciones de movilidad para alcanzar los recursos urbanos que posibiliten la producción y la reproducción sociales.

\section{Caracterización de la población del área de estudio}

Antes de exponer los resultados de la investigación es necesario describir el tejido social del área de estudio, cuyas características socioeconómicas son heterogéneas y comprenden un tejido social microdiferenciado, ya que, como afirma Vignoli Rodríguez, "la movilidad diaria parece tener nexos con el funcionamiento del mercado de trabajo y con el nivel de ingreso de las personas" (2008, p. 58).

Según indica el Instituto Nacional de Estadística e Informática (INEI) en sus Planos Estratificados de Lima Metropolitana a nivel de manzana según ingreso Per Cápita del Hogar y según grupos de pobreza monetaria (2016), "el 57.9\% de la población de este distrito presenta un estrato económico medio y el $35.4 \%$ bajo" (p. 27). Por otro lado, en sus Planos Estratificados de Lima Metropolitana a nivel de manzana según ingreso Per Cápita del Hogar y según grupos de pobreza monetaria (2016), el INEI establece que "el 39\% de su población se encuentra en condición de pobreza" (p. 83).

A partir de los datos proporcionados por el INEI en su Compendio Estadístico (2017), se 
infiere que la población juvenil (de 10 a 29 años) del distrito de Independencia en 2015 representa el $34,5 \%$ del total de la población.

El $6 \%$ de la población del distrito es analfabeta, respecto a lo cual se destaca la zona de El Ermitaño, ubicada al sur del distrito, y que presenta niveles de analfabetismo del orden del $22 \%$, según información del Centro Económico de Lima Norte (2017).

Este distrito presenta una organización de base bien posesionada y fuerte. Registra 88 clubes de madre, en los cuales 2200 socias desarrollan actividades de preparación de alimentos y experiencias productivas en beneficio de la comunidad, de acuerdo con la información proporcionada por el Centro Económico de Lima Norte (2017).

En el campo de la salud, este distrito presenta el 5,7\% de su población menor de 5 años en un estado de desnutrición crónica (INEI, 2009),

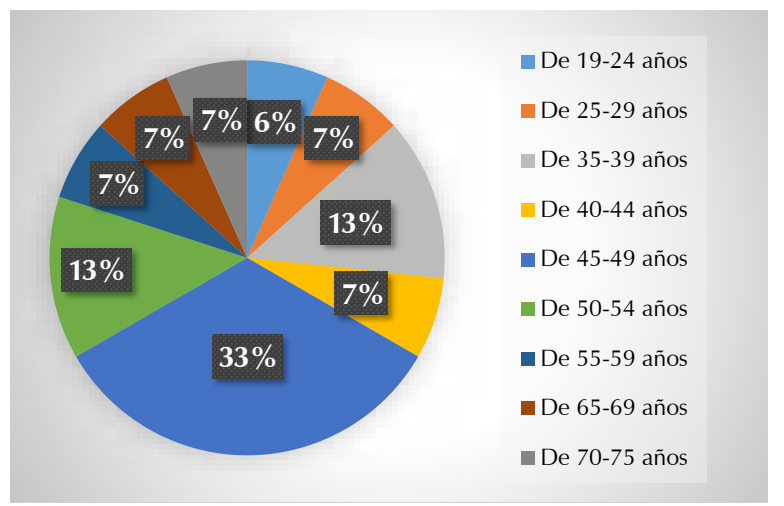

(A) Figura 8. Edades de los entrevistados.

Fuente: elaboración propia (setiembre de 2019).

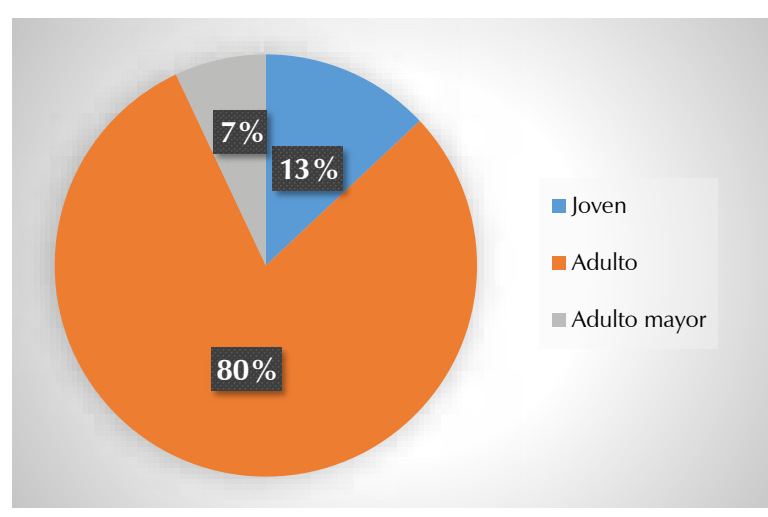

A Figura 10. Mercado informal La paradita.

Fuente: elaboración propia (2019).

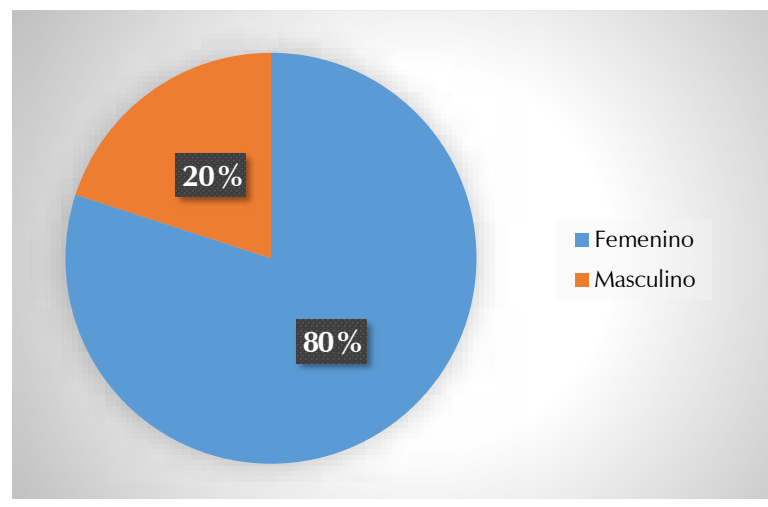

(A) Figura 12. Género de los entrevistados.

Fuente: elaboración propia (enero de 2019). debido, principalmente, a la situación de pobreza que afronta su población.

En el aspecto económico, en 2008, según información del Observatorio Socioeconómico Laboral de Lima Norte, la Población Económicamente Activa del distrito fue del 51,3\%. Así mismo, el $41,4 \%$ estaba subempleada y el desempleo alcanzó el 7,3\%; sin embargo, se estimó que para 2017, el 92,3\% de su población se encontraría económicamente activa (Quispe et al., 2017).

Se determinó que la muestra sería aleatoria, por cuanto el interés radica en investigar el desplazamiento cotidiano de cualquier persona que podría caminar. Se seleccionó una muestra de 15 personas entre los 19 y los 75 años (figura 8), a las cuales se les hizo una entrevista semiestructurada.

La población entrevistada presenta el siguiente perfil socioeconómico: realiza desplazamientos cotidianos, en su mayoría, dentro del sector

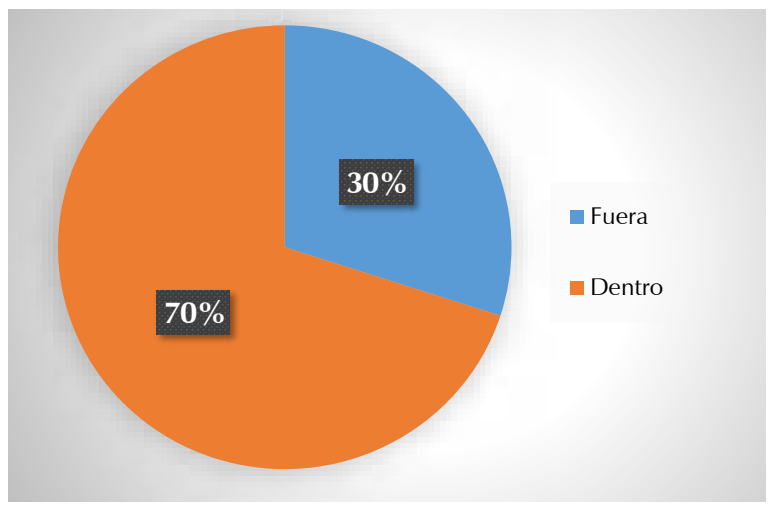

(A) Figura 9. Origen y destino.

Fuente: elaboración propia (enero de 2019).

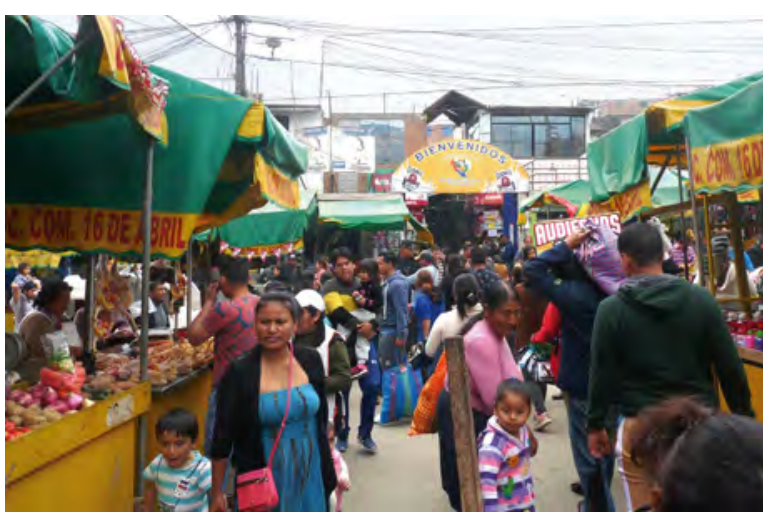

(A) Figura 11. Estructura etaria de los entrevistados. Fuente: elaboración propia (enero de 2019).

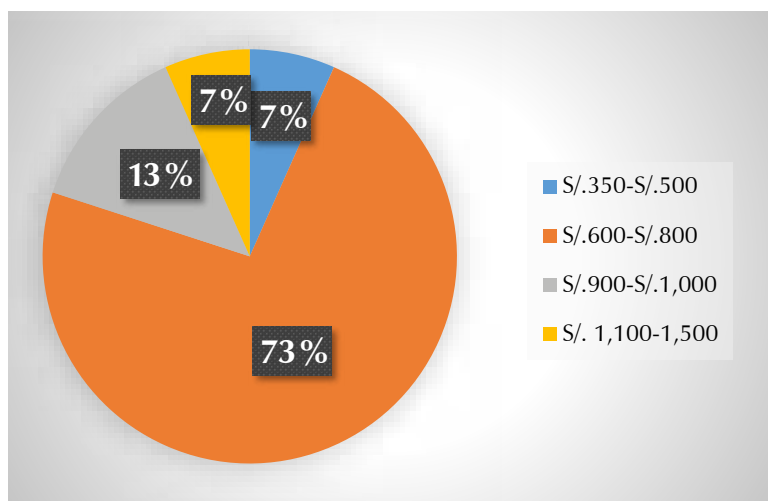

(A) Figura 13. Ingreso per cápita por mes de los entrevistados (en dólares estadounidenses).

Fuente: elaboración propia (enero de 2019). 


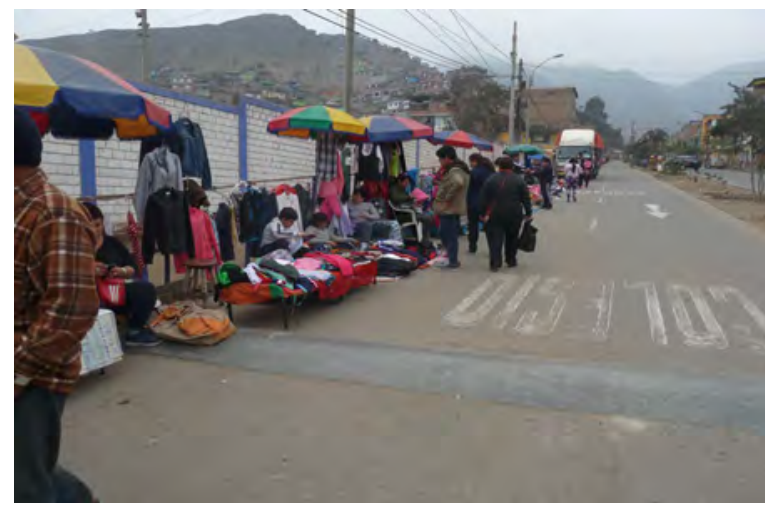

(A) Figura 14. Comercio ambulante.

Fuente: elaboración propia (2019)

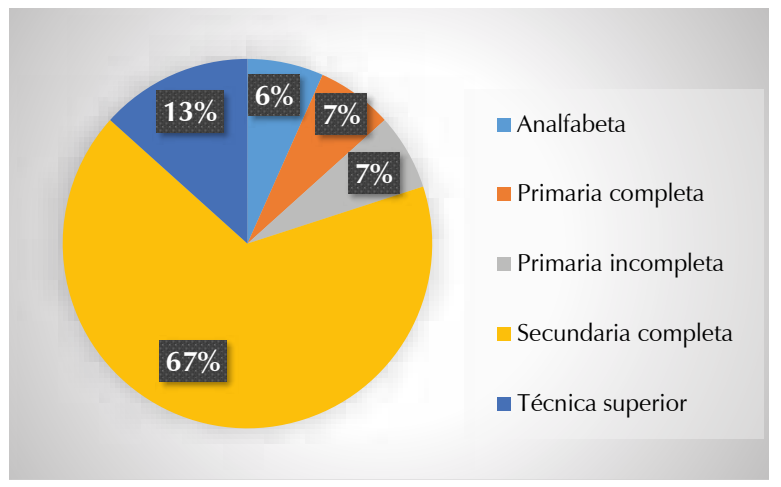

(A) Figura 16. Grado de instrucción de los entrevistados. Fuente: elaboración propia (enero de 2019).

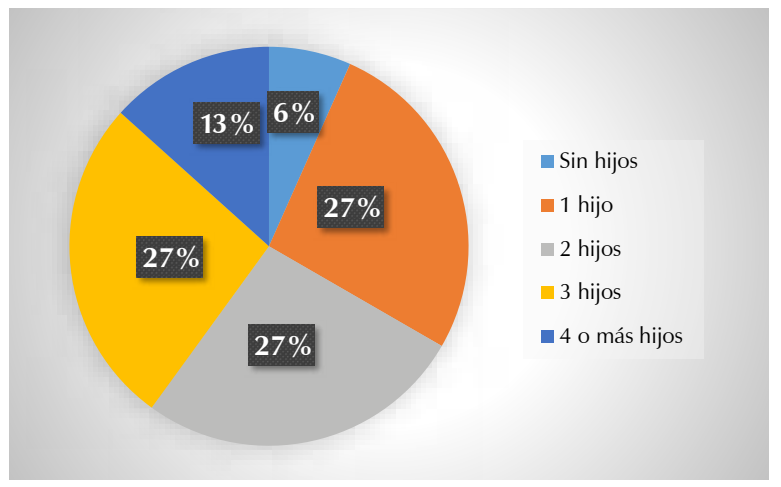

(A) Figura 18. Número de hijos de los entrevistados. Fuente: elaboración propia (enero de 2019).

II de Tahuantinsuyo (figura 9); en especial, a un lugar denominado La paradita. Este espacio es un mercado informal apostado al margen de un mercado formal (figura 10).

Presenta una estructura etaria, con una predominancia de las personas adultas del orden del $80 \%$, y joven, del $33 \%$ (figura 11). El género que predomina es el femenino, con el 50\% (figura 12), población que, a su vez, presenta el mayor desempleo, o que genera su autoempleo, y nacida en una gran proporción en el mismo distrito (80\%).

Esta muestra de población tiene un ingreso per cápita por mes que fluctúa entre los USD 102 y los USD 442 (figura 13). El oficio más recurrente es el de vendedor ambulante, con el 60\% (figuras 14 y 15). El grado de instrucción predominante es el de secundaria, con el $67 \%$ (figura 16). El $27 \%$ de los entrevistados aseguran vivir hace más de 50 años en el sector y el $27 \%$ tiene un tiempo de residencia de uno a 9 años (figura 17). El $54 \%$ de los entrevistados tienen entre 2 y 3 hijos, en promedio (figura 18);

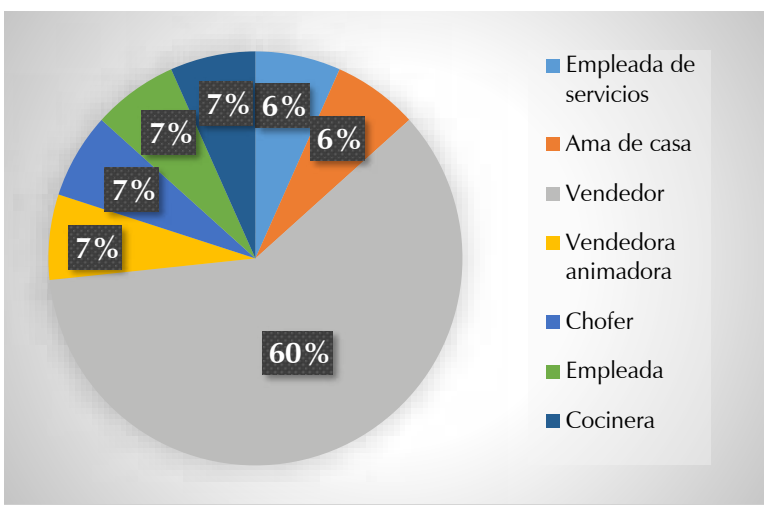

(A) Figura 15. Profesión y oficio de los entrevistados. Fuente: elaboración propia (enero de 2019).

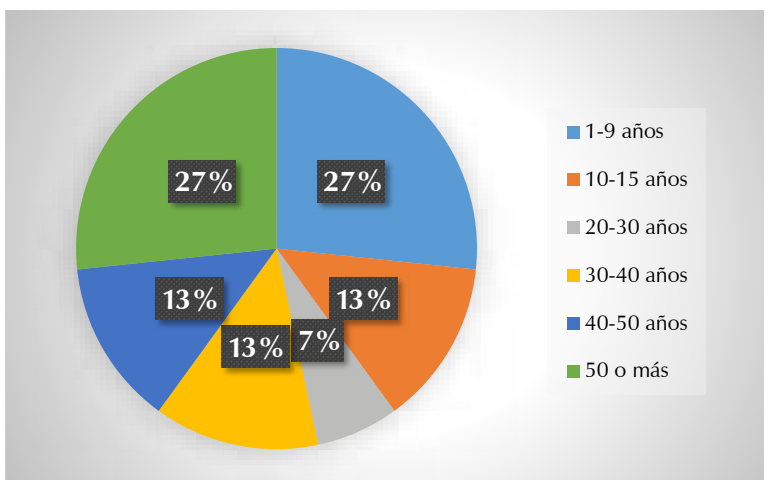

(A) Figura 17. Tiempo de residencia de los entrevistados. Fuente: elaboración propia (enero de 2019).

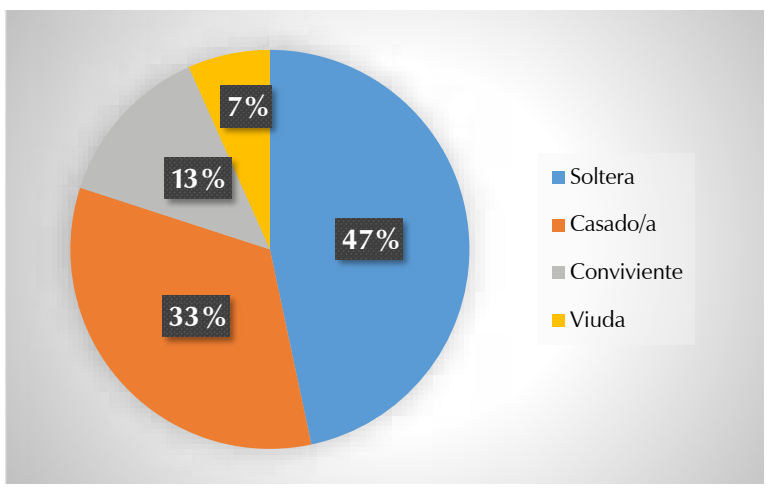

(A) Figura 19. Estado civil de los entrevistados. Fuente: elaboración propia (enero de 2019).

además, presentan un estado civil mayoritariamente soltero con carga familiar, con el $47 \%$ (figura 19).

\section{Resultados}

\section{Condiciones para la movilidad urbana cotidiana}

La población de la zona, en su día a día, se desplaza básicamente a buscar su sustento económico en mercados y a La paradita. Desarrollan el comercio informal y en espacios urbanos inadecuados, pero convenientemente ubicados al lado de comercios formales, y se enfocan en la venta de productos de primera necesidad y productos de segunda mano; sobre todo, vestimenta.

Importante es el nivel de accesibilidad del poblador del área objeto de estudio. El grado de semiconsolidación de dicha área — medido a partir de las condiciones de habitabilidad que ofrecen las viviendas de acuerdo con su nivel de finalización de obra y la capacidad de soporte del entorno, en referencia a la infraestructura de 


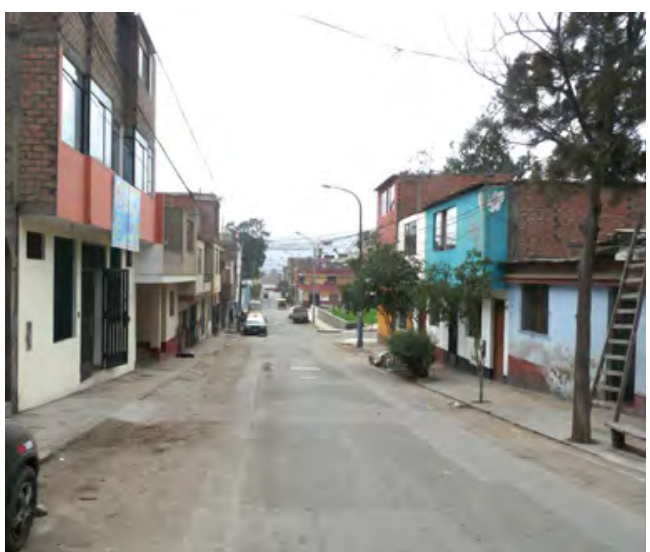

(A) Figura 20. Grado de consolidación urbana: semiconsolidada.
Fuente: elaboración propia (2019).

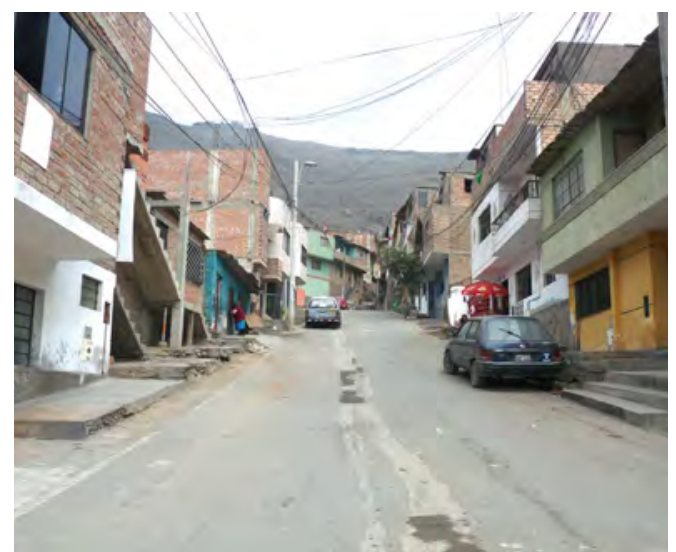

(A) Figura 21. Grado de consolidación urbana: estado de la calzada y veredas.

Fuente: elaboración propia (2019) zar cotidianamente desplazamientos dentro de área de estudio; específicamente, a La paradita: sus veredas y su calzada facilitan desplazamientos regularmente confortables y a diario, a pesar de la topografía (figura 23).

El entorno urbano y su accesibilidad permiten al $40 \%$ de los entrevistados desarrollar trayectos que, en promedio, son cortos: de entre 5 y 10 minutos (figura 28). Además, el $46 \%$ de los pobladores gastan, en promedio, entre USD 0,50 y USD 0,75 (figura 29); el $87 \%$ usa predominantemente el transporte público (figura 30), y dentro de esta modalidad, el $80 \%$ utiliza el transporte de tipo informal (figura 31).

El transporte informal más usado, dentro de lo que se denomina transporte público, es el moto-

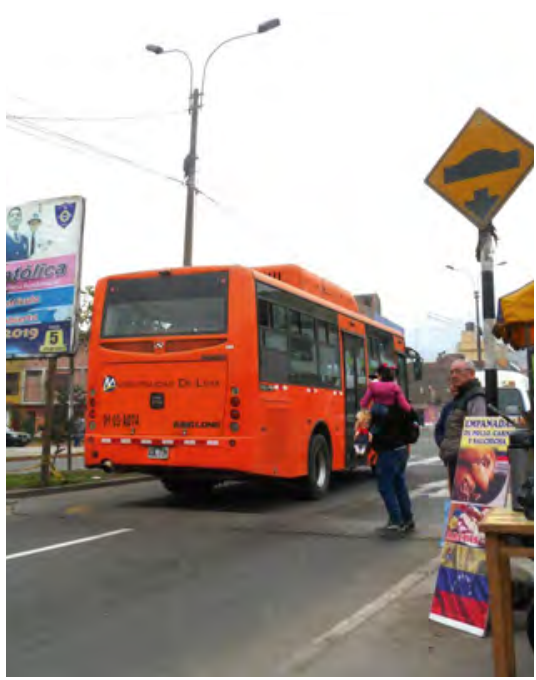

(A) Figura 23. Bus Alimentador del Corredor Segregado de Alta Capacidad (COSAC), El Metropolitano.

Fuente: Elaboración propia (2019).

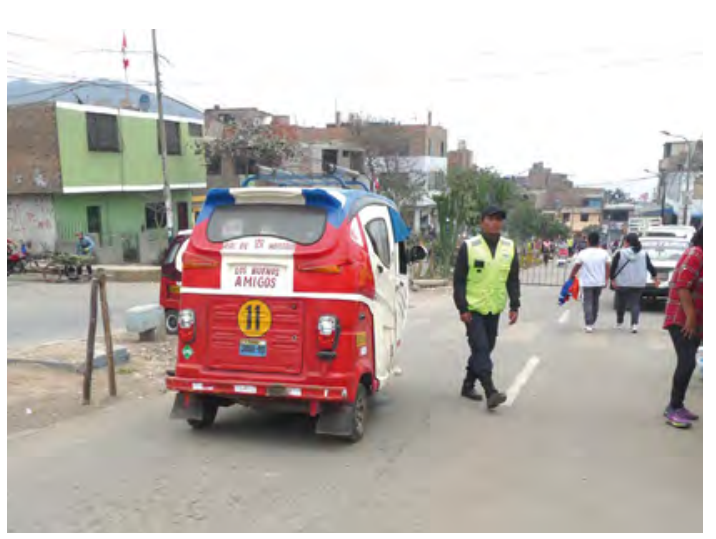

(A) Figura 25. Mototaxis informales.

Fuente: archivo fotográfico del investigador (2019).

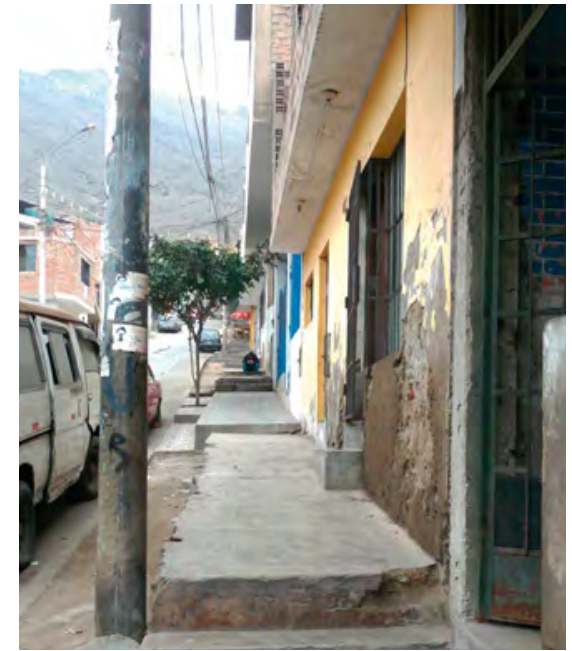

(A) Figura 22. Grado de consolidación urbana: estado de la calzada y veredas. Fuente: elaboración propia (2019).

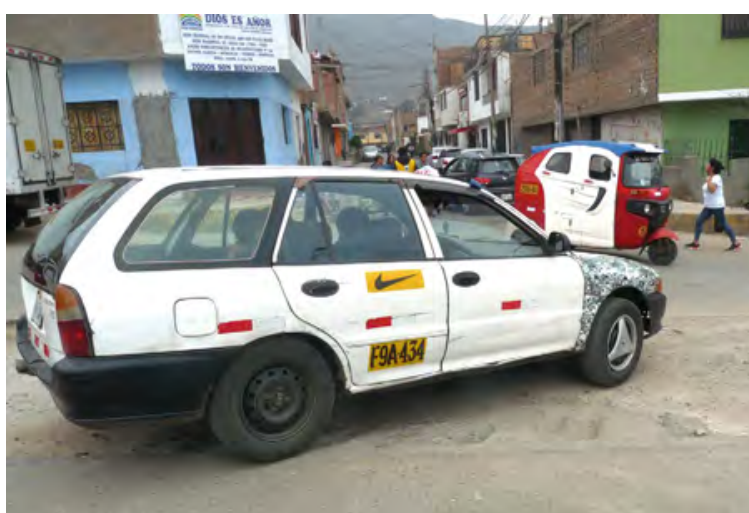

(A) Figura 24. Taxis informales.

Fuente: elaboración propia (2019).

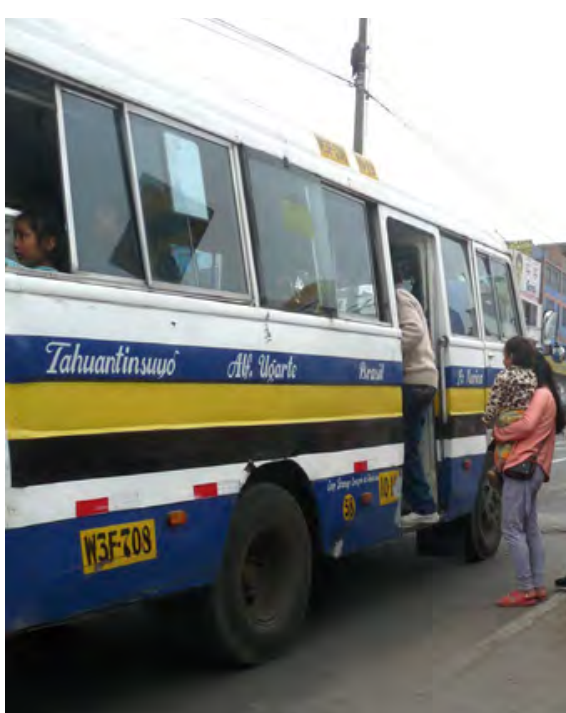

(A) Figura 26. Combis. Fuente: elaboración propia

taxi, lo cual significa que de cada 10 viajes, 8 se hacen por este medio (figura 32). Este vehículo tiene capacidad para unas 17 personas cómodamente sentadas, aunque este tipo de unidades, con la complacencia de sus choferes y de los cobradores, y con la anuencia de los pasajeros, suelen llevar pasajeros de pie.

El $67 \%$ de los entrevistados, usualmente no cambian de ruta (figura 33). El $93 \%$ de ellos realizan 4 trayectos diarios en promedio (figura 34), y el $80 \%$, sin hacer trasbordos (figura 35). Además, el $73 \%$ de los encuestados maneja dispositivos 


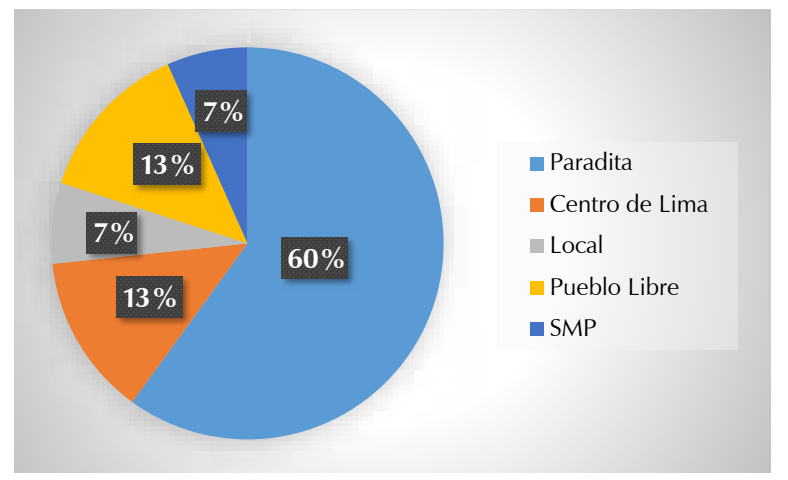

(A) Figura 27. Trayecto cotidiano.

Fuente: elaboración propia (enero de 2019).

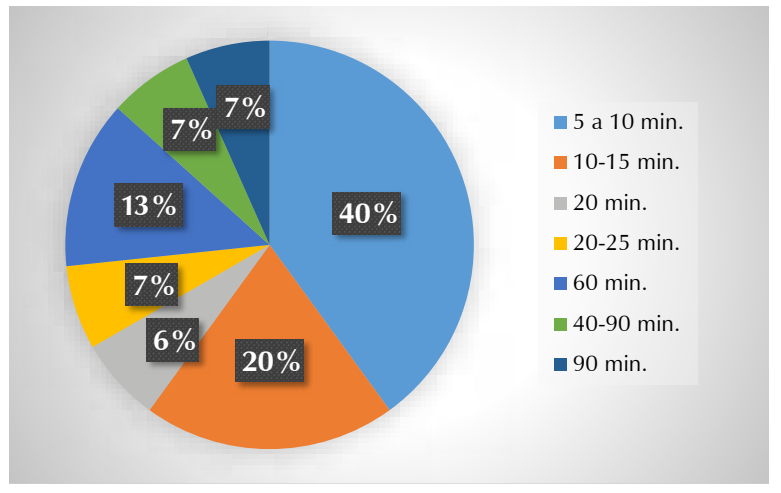

(A) Figura 28. Duración del trayecto cotidiano. Fuente: elaboración propia (enero de 2019).

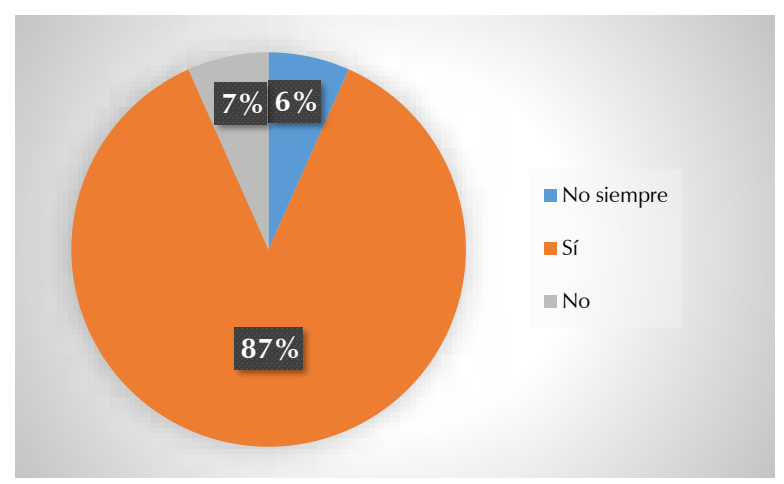

(A) Figura 30. Uso del transporte público.

Fuente: elaboración propia (enero de 2019).

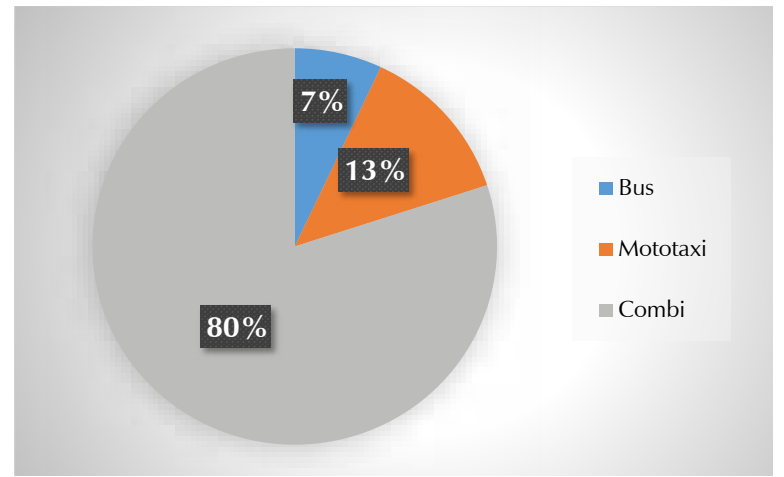

(A) Figura 32. Modos de transporte motorizado usados cotidianamente.

Fuente: elaboración propia (enero de 2019).

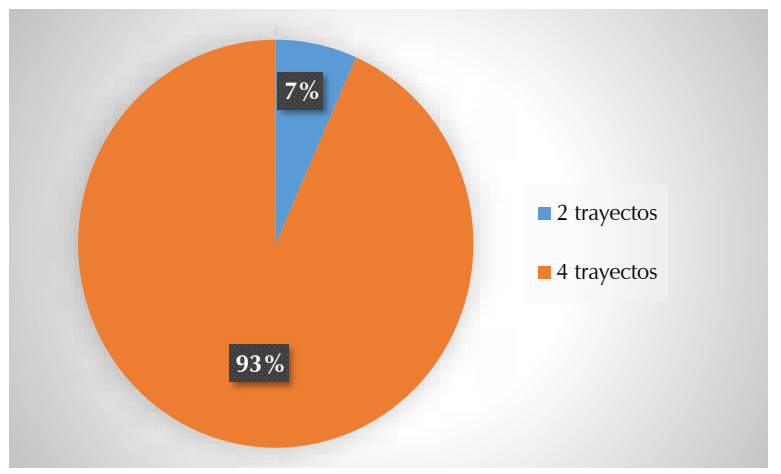

(4) Figura 34. Trayectos diarios.

Fuente: elaboración propia (enero de 2019). (figura 36), tales como tarjetas del Metropolitano o el tren, pero, en su mayoría (el $73 \%$ de los pobladores), hacia su lugar de trabajo o hacia el paradero, prefieren los viajes a pie (figura 37).

En cuanto a la propiedad de algún modo de transporte, el $80 \%$ de los entrevistados no cuenta con algún medio de transporte personal; sin embargo, el $13 \%$ tiene bicicleta, pero podemos observar que no la usa, por razones de seguridad vial (figura 38).

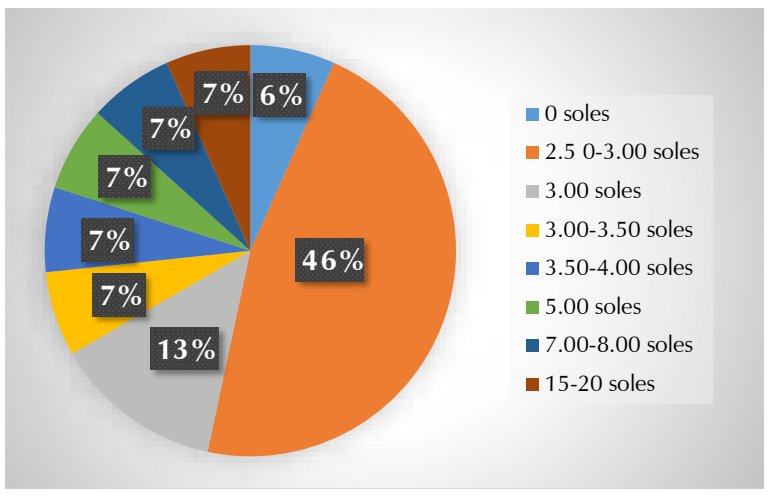

(4) Figura 29. Gasto promedio por trayecto. Fuente: elaboración propia (enero de 2019).

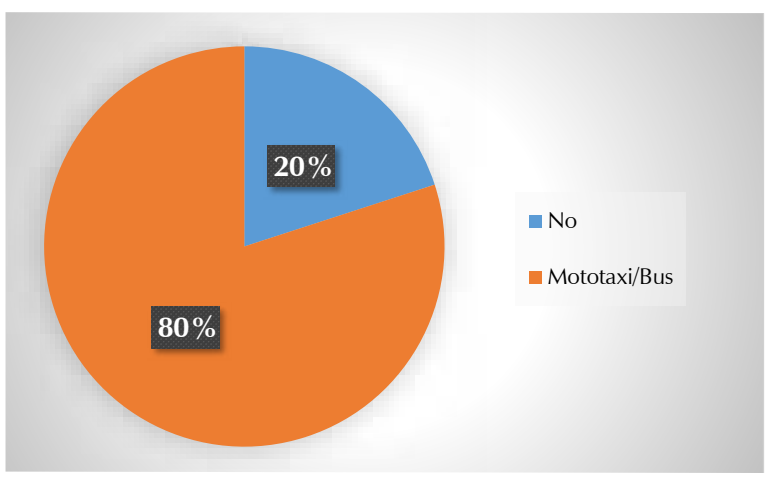

(A) Figura 31. Uso del transporte informal.

Fuente: elaboración propia (enero de 2019).

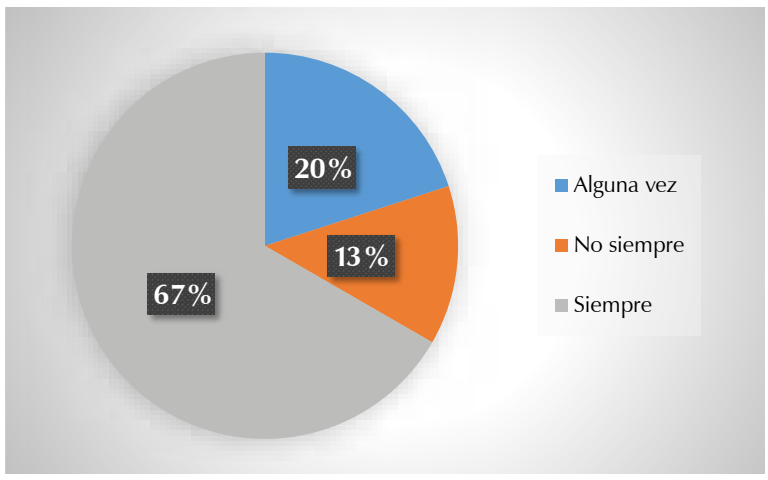

(A) Figura 33. Cambio de ruta.

Fuente: elaboración propia (enero de 2019).

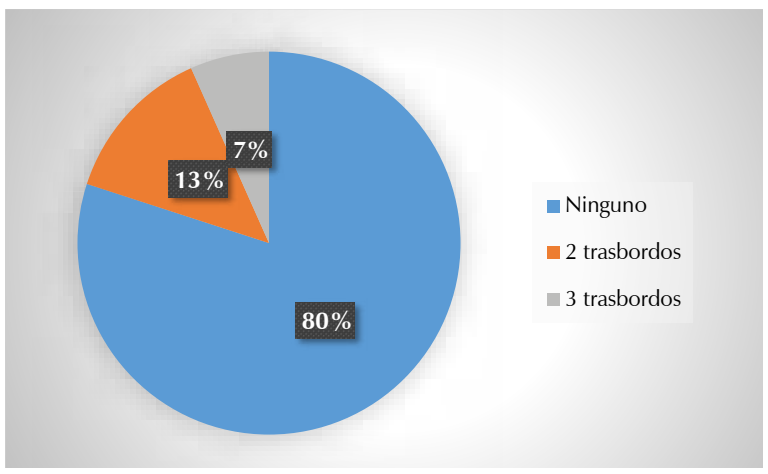

(A) Figura 35. Trasbordos en desplazamientos hacia el trabajo. Fuente: elaboración propia (enero de 2019). 


\section{Competencias}

Las destrezas y las habilidades incluyen las competencias que desarrollan los individuos para efectuar desplazamientos. Estas incluyen: competencias físicas y de buena salud, conocimientos de informática, aplicaciones, internet, y de organización para el desplazamiento, todas las que podemos construir de la mano de nuestros vecinos, nuestros colegas de trabajo y nuestros familiares (figuras 39 y 40).

Los pobladores de la II zona de Tahuantinsuyo presentan habilidades y competencias varias, tales como: estar en buenas condiciones física y de salud, pues el $80 \%$ reconoce que se encuentra en buenas condiciones físicas para realizar sus desplazamientos (figura 39). Más de la mitad (60\%) de la población entrevistada no sufre de dolencia alguna ni tiene tampoco algún tipo de discapacidad (figura 40).

El $80 \%$ conoce a plenitud su barrio y se siente en libertad y comodidad para realizar sus trayectos cotidianos (figura 41). El $80 \%$ de la muestra conoce la ruta de la mayoría de líneas de transporte público (figura 42).

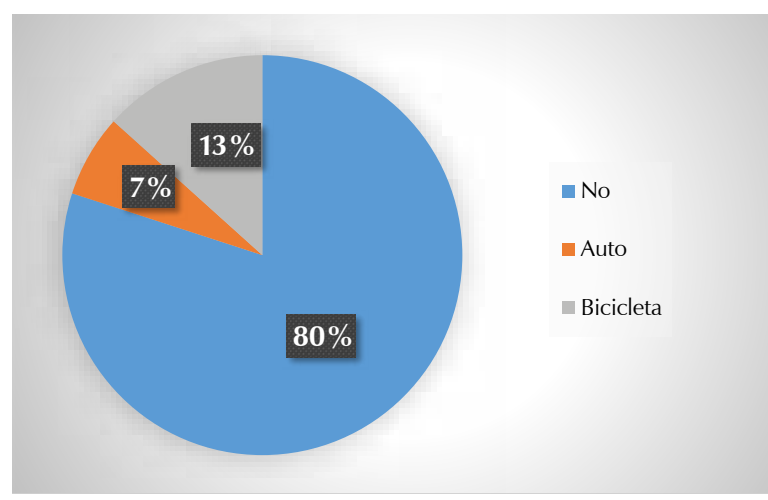

(4) Figura 38. Propiedad de otros modos de transporte personal. Fuente: elaboración propia (enero de 2019).

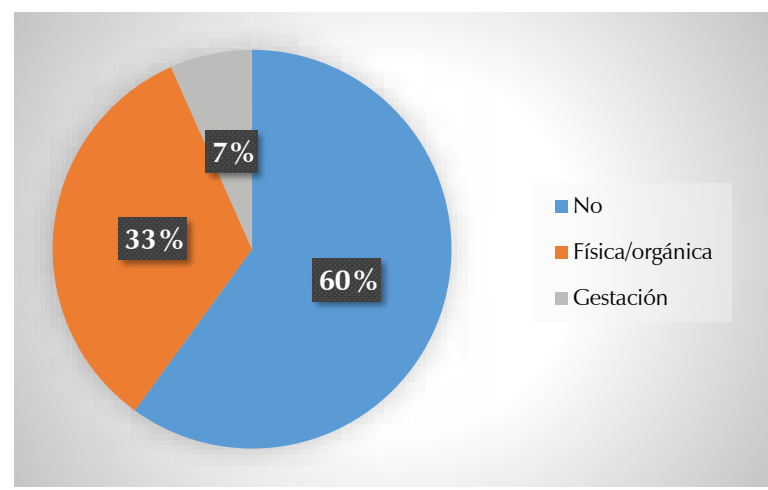

(4) Figura 40. Discapacidad y condición médica. Fuente: elaboración propia (enero de 2019).

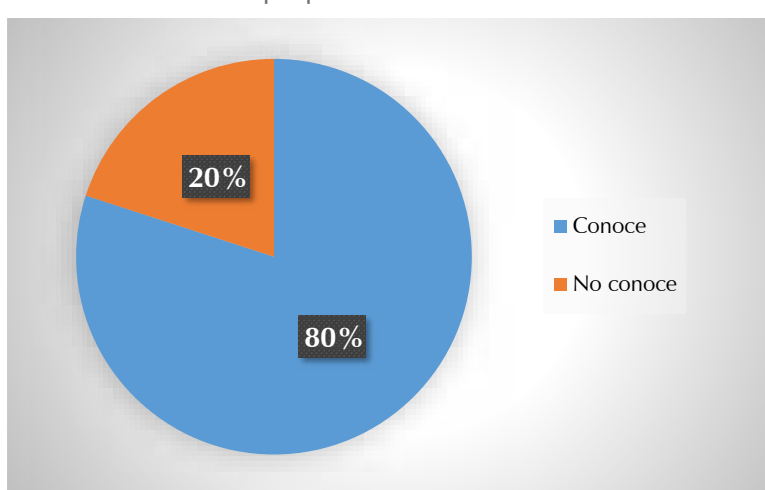

(A) Figura 42. Conocimiento de las rutas de transporte. Fuente: elaboración propia (enero de 2019).

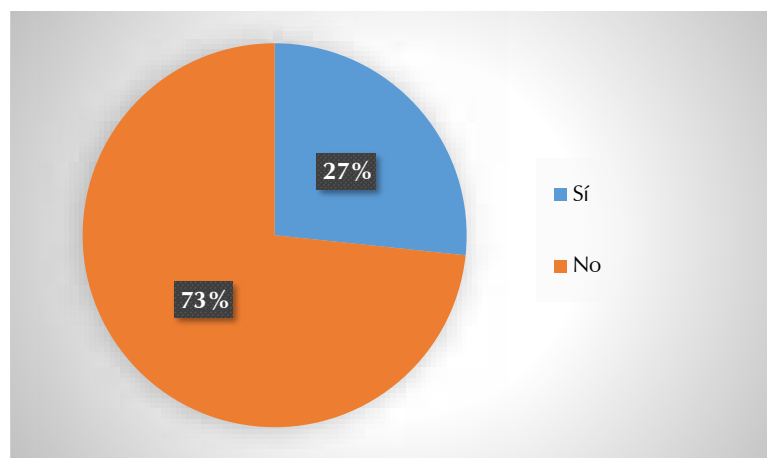

(A) Figura 36. Manejo de dispositivos tecnológicos para la movilidad.

Fuente: elaboración propia (enero, 2019).

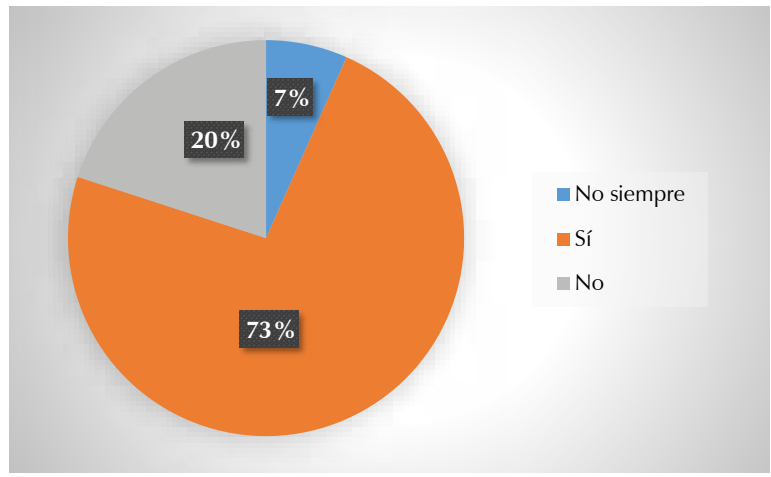

(A) Figura 37. Trayectos a pie.

Fuente: elaboración propia (enero de 2019).

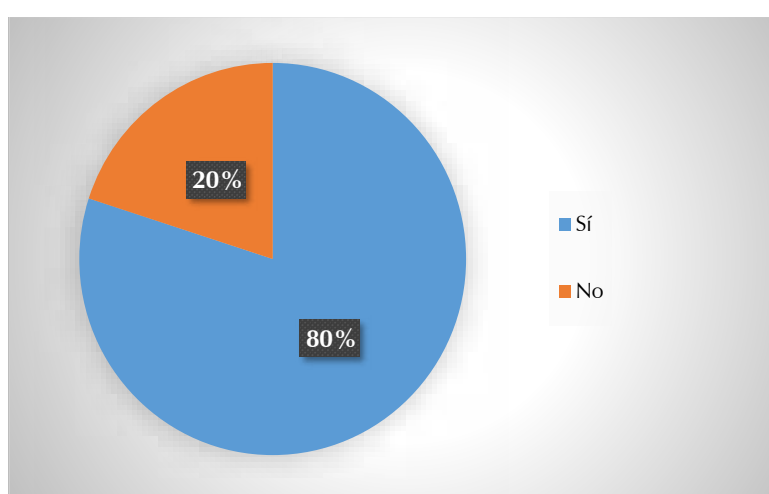

(A) Figura 39. Buena condición física.

Fuente: elaboración propia (enero de 2019).

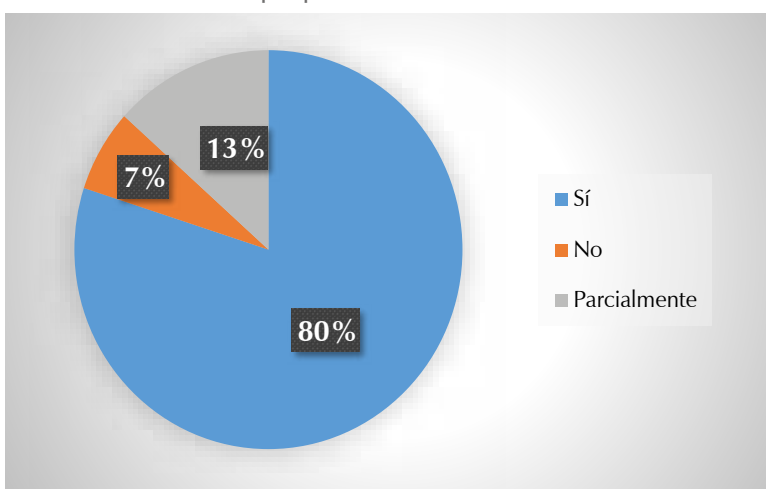

(A) Figura 41. Conocimiento del entorno barrial.

Fuente: elaboración propia (enero de 2019).

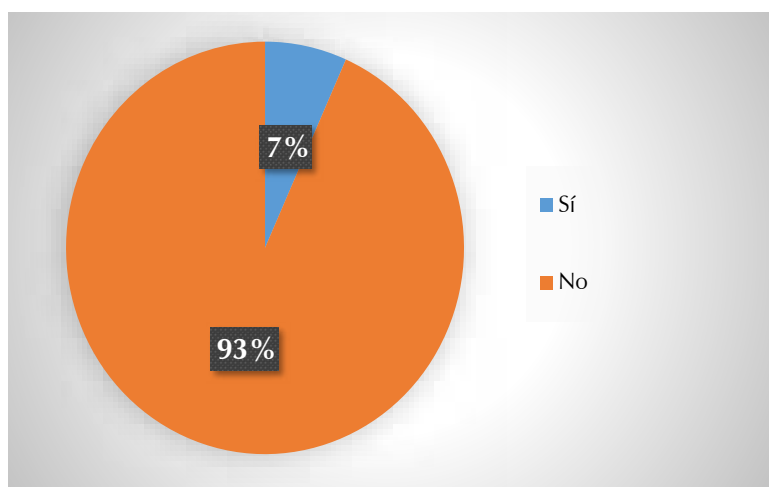

(A) Figura 43. Posesión de licencia de conducir. Fuente: elaboración propia (enero de 2019). 


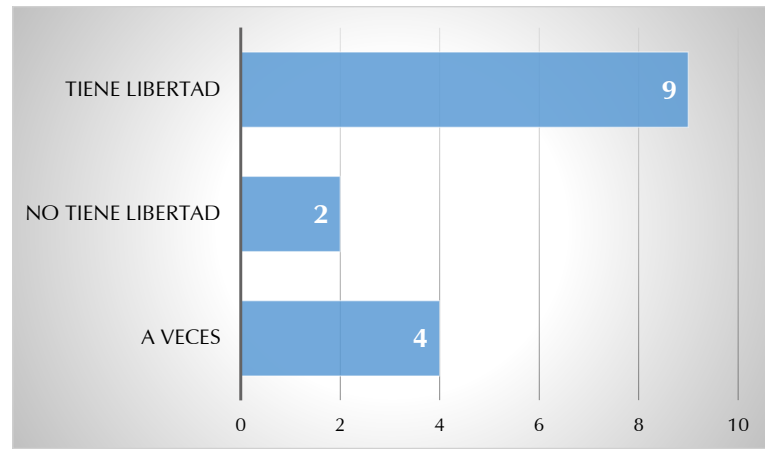

(4) Figura 44. Libertad para tomar decisiones de desplazamiento. Fuente: elaboración propia (enero de 2019).

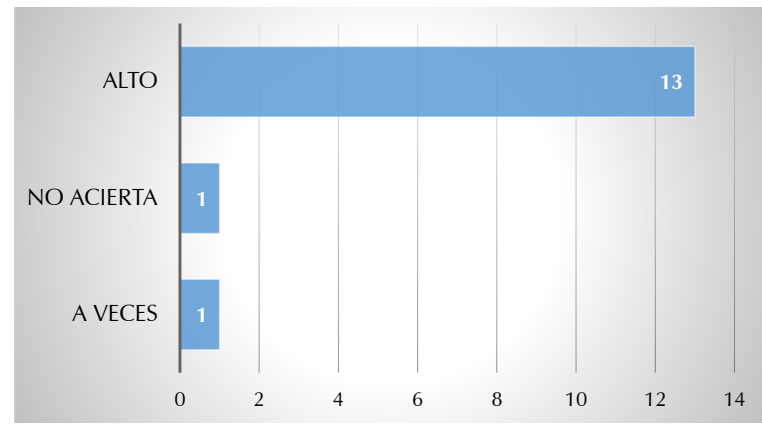

(A) Figura 46. Nivel de asertividad para la escogencia modal. Fuente: elaboración propia (enero de 2019).

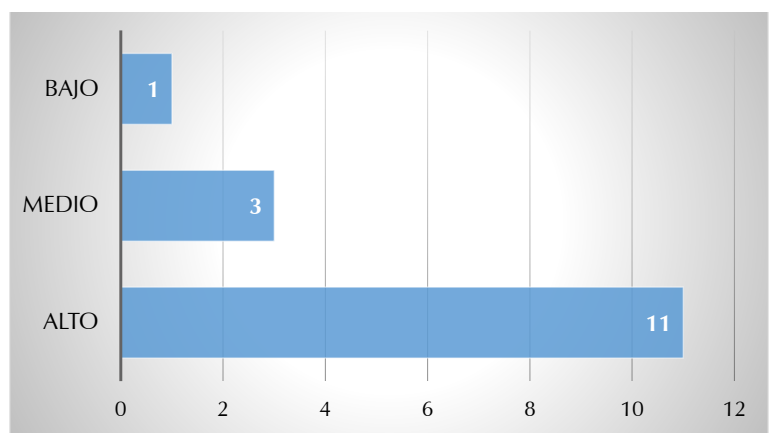

(A) Figura 48. Grado de autonomía para efectuar desplazamientos. Fuente: elaboración propia (enero de 2019).

Por otro lado, el $7 \%$ de los entrevistados manifiesta tener licencia de conducir, condición que marca una diferencia sustancial frente al individuo que no sabe conducir y podrá influir en un aumento de su capital de motilidad (figura 43).

\section{Agencia}

En cuanto a la agencia, se observó que la mayoría de los pobladores entrevistados entienden que tienen libertad para tomar las decisiones que involucren desplazamientos (figura 44). Además, casi el total de los entrevistados tiene un alto grado de negociación a favor de sus desplazamientos; es decir, pueden desde regatear el costo hasta solicitar al conductor que se detenga en paraderos no reglamentados (figura 45).

En cuanto al nivel de asertividad para escoger el modo de transporte, la mayoría de los pobladores seleccionados ostentan un alto grado de certeza para escoger el modo de transporte que los llevará a su destino dentro de su zona de residencia, así como fuera de ella (figura 46); sin embargo, la mayoría considera que al desarrollar sus desplazamientos no son muy eficaces, pues factores como la distancia hasta los paraderos, la

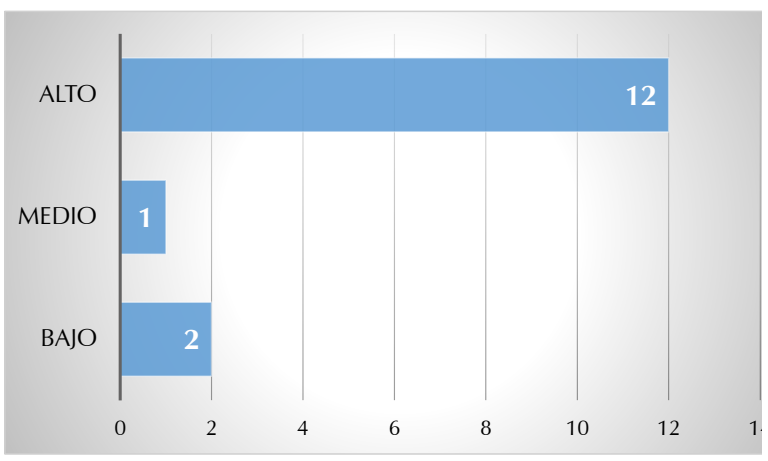

(A) Figura 45. Grado de negociación para efectuar desplazamientos. Fuente: elaboración propia (enero de 2019).

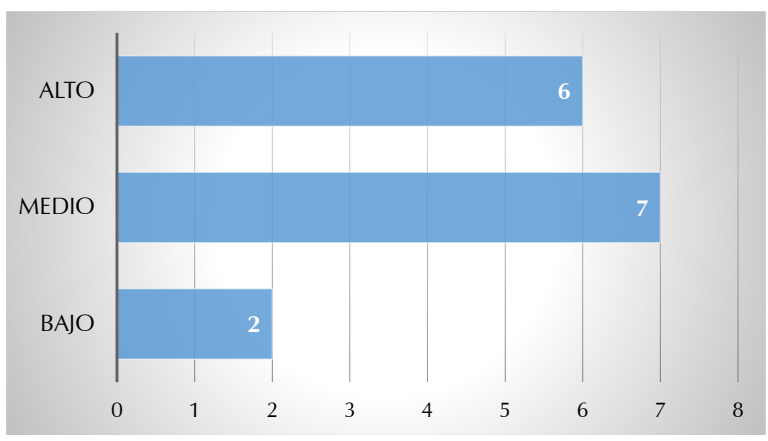

(A) Figura 47. Nivel de autoeficacia en los desplazamientos. Fuente: elaboración propia (enero de 2019).

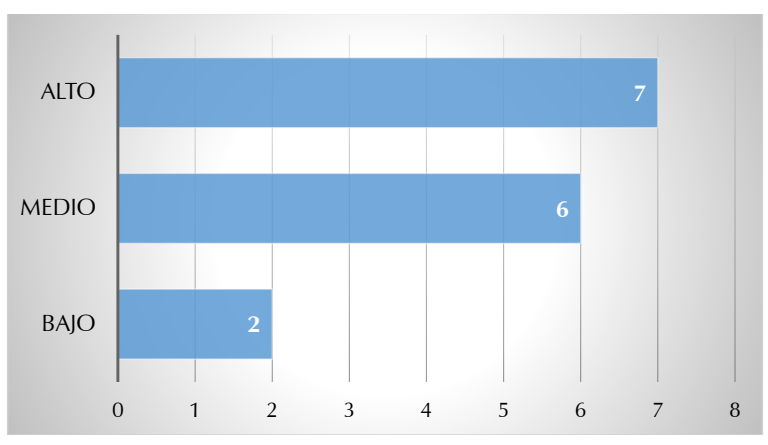

(A) Figura 49. Grado de control para efectuar desplazamientos. Fuente: elaboración propia (enero de 2019).

topografía y el estado de las veredas y de las calzadas les juegan en contra en medio del intento de abordar las unidades de transporte (figura 47).

La mayoría de los pobladores de esta zona ostenta un alto grado de autonomía para efectuar desplazamientos; es decir, pueden decidir cuándo, a qué hora y dónde ir (figura 48). Aproximadamente la mitad de dicha población seleccionada considera que tiene un alto control de sus desplazamientos, mientras que menos de la otra mitad considera que solo tiene un grado medio de control; probablemente, por la informalidad del transporte, que no siempre recorre las rutas programadas, o por los tiempos de desplazamientos, que no son uniformes (figura 49).

El nivel de autodeterminación en la mayoría de los entrevistados es alto: la tercera parte piensa que su nivel de autodeterminación es medio, lo cual podría deberse, básicamente, al ingreso per cápita que ostentan (figura 50). Por otro lado, el nivel de pensamiento independiente es bastante alto en la muestra, pues casi la totalidad de los entrevistados pueden pensar en su desplazamiento en cualquier momento del día (figura 51). 


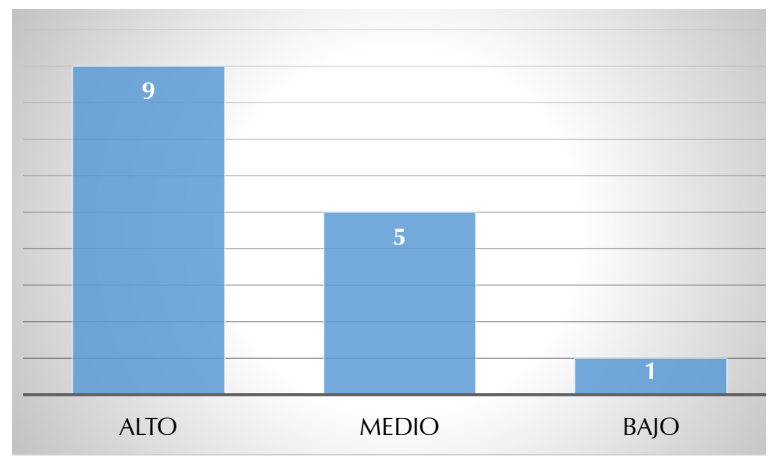

(A) Figura 50. Nivel de autodeterminación para efectuar desplazamientos.

Fuente: elaboración propia (enero de 2019).

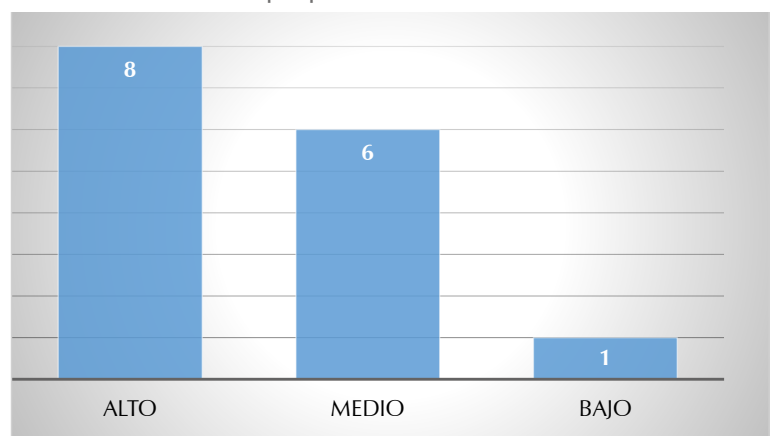

(A) Figura 52. Grado de identificación de necesidad de cambio para efectuar desplazamientos.

Fuente: elaboración propia (enero de 2019).

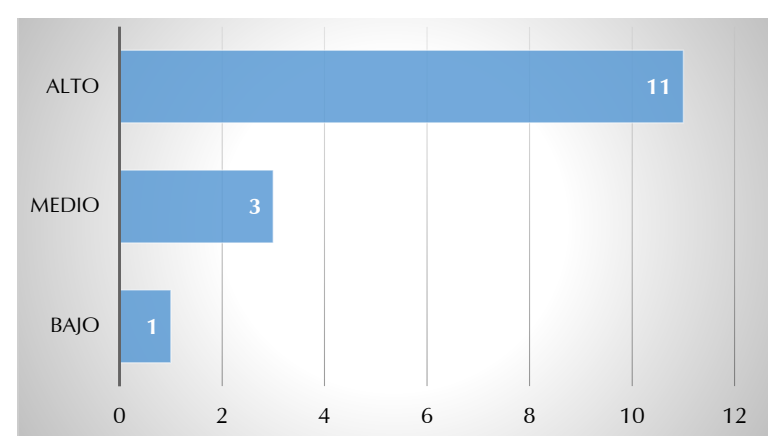

(A) Figura 54. Nivel de percepción de mi contexto.

Fuente: elaboración propia (enero de 2019).

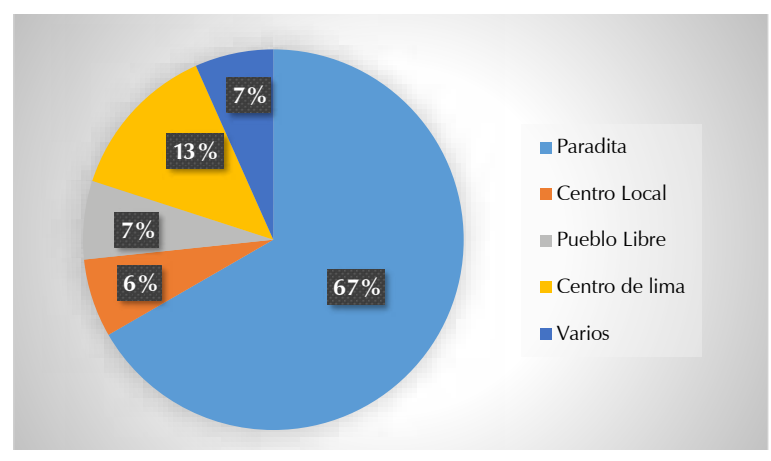

(A) Figura 56. Destino del desplazamiento cotidiano. Fuente: elaboración propia (enero de 2019).

Pese a lo planteado, casi la totalidad de los entrevistados consideran que deberían cambiar sus rutas de desplazamientos hacia otros barrios contiguos, buscando solventar sus propias necesidades de trabajo (figura 52). Así mismo, la mitad de la muestra considera que no tiene control sobre su entorno, pues su campo de movilidad cotidiana está regido por la informalidad (figura 53). Además, el nivel de percepción sobre el conocimiento del espacio urbano es alto, lo que permite al poblador resolver los problemas de desplazamiento cotidiano con destino al trabajo (figura 54).

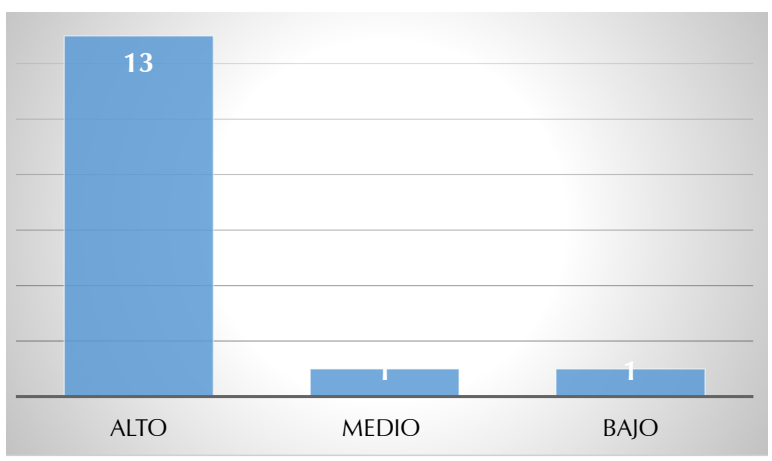

(A) Figura 51. Nivel de pensamiento independiente para efectuar desplazamientos.

Fuente: elaboración propia (enero de 2019)

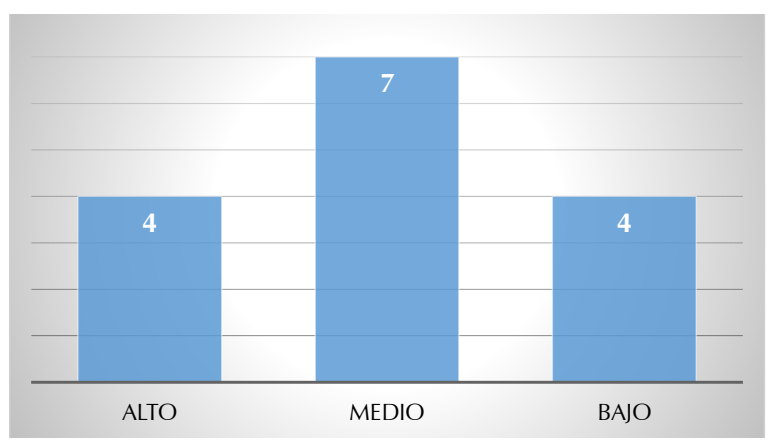

(A) Figura 53. Nivel de control sobre mi entorno.

Fuente: elaboración propia (enero de 2019).

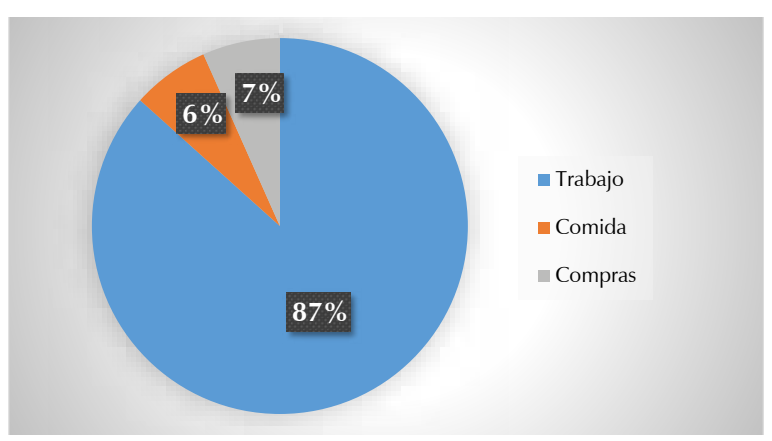

(A) Figura 55. Motivo de desplazamiento.

Fuente: elaboración propia (enero de 2019).

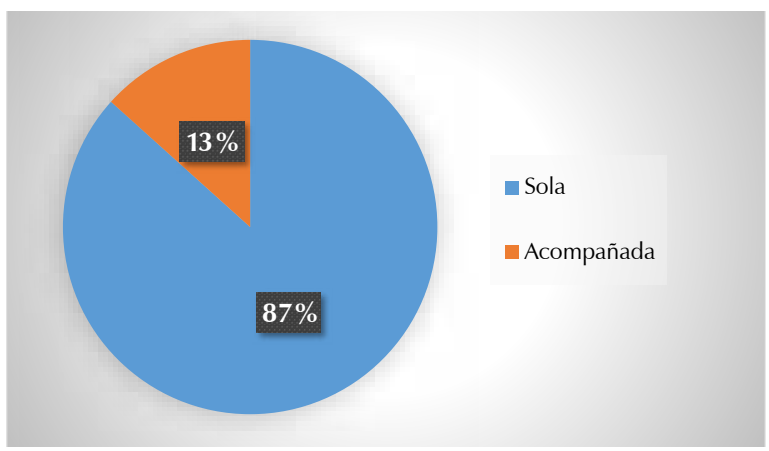

(A) Figura 57. Acompañamiento del desplazamiento cotidiano. Fuente: elaboración propia (enero de 2019).

\section{Apropiación}

En cuanto a la apropiación, esta es definida como la capacidad del individuo para interpretar su propio grado de movilidad, de manera que le otorgue poder, dominación y acción social sobre otros individuos que también requieren moverse; es decir, quienes tienen capacidad de apropiación adquieren empoderamiento sobre sus propias condiciones de movilidad urbana cotidiana.

La población entrevistada manifiesta que en el $87 \%$ de los casos, su motivo sustancial para desarrollar desplazamientos diarios es el trabajo (figura 


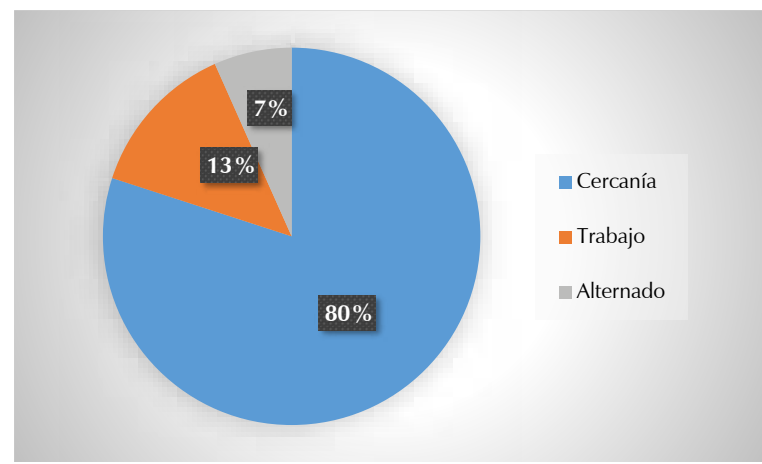

(A) Figura 58. Elección del lugar de destino.

Fuente: elaboración propia (enero de 2019).

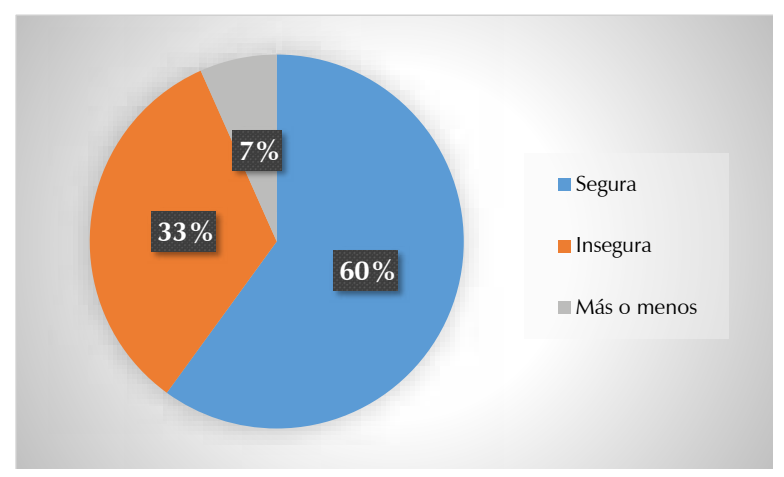

(A) Figura 60. Percepción de seguridad al desarrollar trayectos. Fuente: elaboración propia (enero de 2019).

$55)$; en el $67 \%$, estas personas se apropian de un espacio público conocido como La paradita, en la que realizan la actividad de comercio ambulante (figura 56). El $87 \%$ suelen realizar sus desplazamientos solos, pues se sienten empoderados para ejercer su movilidad cotidiana (figura 57).

La mayoría de la población entrevistada se siente empoderada en su barrio, en su entorno inmediato; más precisamente, si se refieren a La paradita, porque es un sitio cercano. Por tal razón deciden desplazarse $(80 \%)$ : porque perciben que el barrio es seguro (67\%); también, porque el trayecto que realizan hacia dicho espacio de "trabajo" es seguro $(60 \%)$ y porque el $73 \%$ de los entrevistados opinan que pueden interactuar con toda libertad con otras personas en el trayecto (figuras 58 a 61).

\section{Capital de motilidad}

Después de reducir la información se procedió a codificarla. Se obtuvieron así los resultados para la accesibilidad, las competencias, la agencia y la apropiación, y, por ende, se estableció la cantidad de capital de motilidad de cada uno de los entrevistados. Estas precisiones fueron establecidas de acuerdo con los resultados de las tablas de doble entrada por cada categoría (Accesibilidad, Competencias, Agencia y Apropiación) y cada subcategoría, y comparándolas con el perfil socioeconómico de los entrevistados, como lo muestra la tabla 1.

Los datos expuestos en la tabla 1 muestran algunos resultados relevantes, como el capital de motilidad que ostentan los pobladores de la II zona de Tahuantinsuyo, distrito de Independencia, los cuales, de acuerdo con los valores obtenidos, se pueden clasificar en: alto, medio y bajo, respecto a la moda obtenida. Los valo-

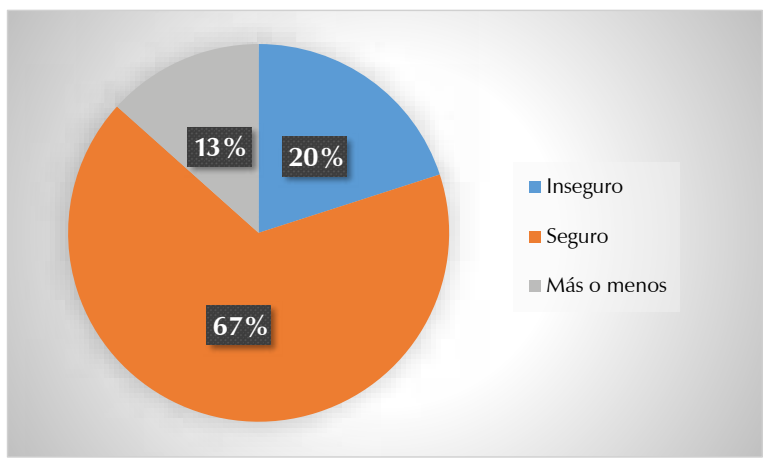

(A) Figura 59. Percepción de seguridad en el barrio. Fuente: elaboración propia (enero de 2019).

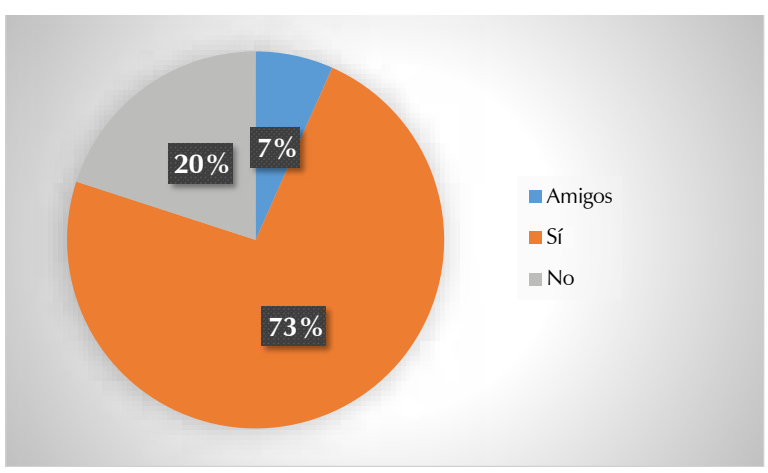

A Figura 61. Interacción social en el trayecto cotidiano. Fuente: elaboración propia (enero de 2019).

res para un capital de motilidad "alto" fluctúan entre 59 y 61 puntos; para "medio", entre los 51 y los 60 puntos, y para "bajo", entre los 47 y los 50 puntos. Todo ello, tomando en cuenta que los factores que definen, por adición, el capital de motilidad son las habilidades o las competencias, así como la accesibilidad al entorno inmediato y a las redes de movilidad.

El 50\% de los entrevistados ostentan un capital de motilidad "medio" respecto a los valores con mayor frecuencia dentro de la distribución de los valores totales, cuyos valores fluctúan entre los 51 y los 58 puntos. Estas son personas con edades que oscilan entre los 23 y los 65 años; es decir, joven adulto, adulto y adulto mayor; el $90 \%$ de estos pobladores tiene educación secundaria, presentan una antigüedad de residencia que oscila en el rango de entre los 36 y los 65 años, y en su totalidad tienen carga familiar.

El $30 \%$ de los entrevistados presentan un capital de motilidad "alto" respecto a los valores con mayor frecuencia dentro de la distribución de los valores totales, cuyos valores fluctúan entre los 59 y los 61 puntos. Estas son personas con edades que oscilan entre los 29 y los 50 años; es decir, joven, joven adulto y adulto. La totalidad de estos pobladores tienen educación secundaria, presentan una antigüedad de residencia que se encuentra en el rango de entre los 8 y los 47 años, y el $90 \%$ de ellos presentan carga familiar.

El 20\% de los entrevistados ostentan un capital de motilidad "bajo" respecto a los valores con mayor frecuencia dentro de la distribución de los valores totales, cuyos valores fluctúan entre los 47 y los 50 puntos. Estas son personas con edades que oscilan entre los 48 y los 73 años; es decir, adulto y adulto 


\begin{tabular}{|c|c|c|c|c|c|c|c|c|c|c|c|c|}
\hline \multicolumn{8}{|c|}{ Perfil socio-económico } & \multirow[b]{2}{*}{ 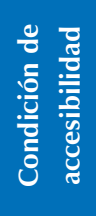 } & \multirow[b]{2}{*}{ 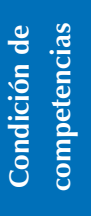 } & \multirow[b]{2}{*}{ 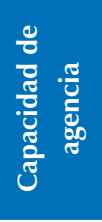 } & \multirow[b]{2}{*}{ 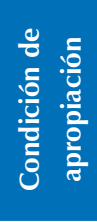 } & \multirow[b]{2}{*}{ 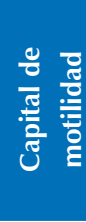 } \\
\hline $\begin{array}{c}\text { Perfil } \\
\text { socioeconómico, } \\
\text { entrevistado }\end{array}$ & $\begin{array}{l}\text { Profesión } \\
\text { u oficio }\end{array}$ & $\begin{array}{c}\text { Ingreso } \\
\text { promedio } \\
\text { mensual } \\
(\mathrm{S} / .)\end{array}$ & Actividad laboral & $\begin{array}{l}\text { Tiempo } \\
\text { de } \\
\text { residencia } \\
\text { (años) }\end{array}$ & $\begin{array}{c}\text { Grado } \\
\text { de } \\
\text { instrucción }\end{array}$ & $\begin{array}{l}\text { Estado } \\
\text { civil }\end{array}$ & Hijos & & & & & \\
\hline Adriana (46) & $\begin{array}{l}\text { Empleada } \\
\text { doméstica }\end{array}$ & 800 & $\begin{array}{l}\text { Trabajadora de } \\
\text { limpieza }\end{array}$ & 40 & $\begin{array}{l}\text { Técnica } \\
\text { Superior }\end{array}$ & Soltera & 2 & 23 & 17 & 19 & 40 & 59 \\
\hline Consuelo (43) & Cocinera & 1500 & $\begin{array}{l}\text { Cocinera en } \\
\text { mercado }\end{array}$ & 18 & Secun. & Soltera & 1 & 19 & 13 & 15 & 32 & 47 \\
\hline Jacinta (50) & Vendedora & 600 & Ventas & 12 & $\begin{array}{c}\text { 2do } \\
\text { primaria }\end{array}$ & Soltera & 3 & 14 & 18 & 17 & 32 & 49 \\
\hline María (36) & Empleada & 800 & Empleada pública & 36 & Secun. & Soltera & 2 & 13 & 13 & 13 & 26 & 39 \\
\hline Javier Vicente (48) & Vendedor & 600 & Ventas & 8 & Secun. & Casada & 1 & 10 & 18 & 15 & 28 & 43 \\
\hline Milagros (47) & Vendedora & 600 & Ventas & 15 & Secun. & Soltera & 4 & 21 & 13 & 16 & 34 & 50 \\
\hline Fanny (23) & $\begin{array}{l}\text { Vendedora/ } \\
\text { animadora }\end{array}$ & 800 & $\begin{array}{c}\text { Independiente/ } \\
\text { venta }\end{array}$ & 23 & Secun. & Conviviente & 1 & 26 & 14 & 18 & 40 & 58 \\
\hline Ada María (55) & Ama de casa & 600 & Ventas & 55 & Secun. & Casada & 2 & 11 & 13 & 12 & 24 & 36 \\
\hline Luis Enrique (47) & Chofer & 1000 & Taxista & 47 & Secun. & Casado & 3 & 23 & 18 & 20 & 41 & 61 \\
\hline Gilmer (29) & Vendedor & 1000 & Ventas/ Limpieza & 8 & Secun. & Soltero & $\mathrm{NO}$ & 14 & 19 & 17 & 33 & 50 \\
\hline Maribel (38) & Vendedora & 600 & Ventas & 38 & Secun. & Casada & 3 & 20 & 11 & 14 & 31 & 45 \\
\hline Susana (65) & Vendedora & 600 & Ventas & 65 & Superior & Soltera & 1 & 12 & 15 & 14 & 27 & 41 \\
\hline Claudia (46) & Vendedora & 600 & Ventas & 9 & Secun. & Conviviente & 3 & 22 & 15 & 17 & 37 & 54 \\
\hline
\end{tabular}

mayor. El 100\% de estos pobladores tienen educación secundaria, presentan una antigüedad de residencia que se encuentra en el rango de entre los 8 y los 58 años y en su totalidad tienen carga familiar.

En otro sentido, los valores para una condición de accesibilidad "alto" fluctúan entre 21 y 26 puntos; para "medio", entre los 16 y los 20 puntos, y "bajo", entre los 10 y los 15 puntos, en referencia a la accesibilidad al entorno inmediato y a las redes de movilidad.

Cabe precisar, de acuerdo con lo mencionado anteriormente que, el $60 \%$ de los pobladores que presentan un capital de motilidad "alto" ostentan niveles de accesibilidad "alto". Así mismo, el 40\% de los pobladores que presentan un capital de motilidad "medio" ostentan niveles de accesibilidad "bajo".

Con relación a los valores para una condición de habilidades y competencias, un valor "alto" fluctúa entre los 17 y 19 puntos; para "medio", entre los 13 y los 16 puntos, y para "bajo", entre los 9 y los 12 puntos, en referencia a la condición física, el grado de instrucción, el conocimiento del barrio, etc.

Es de resaltar que el $60 \%$ de los pobladores que presentan un capital de motilidad "alto" ostentan condición de habilidades y competencias "alto".

Un dato interesante que resaltar se refiere a que el $70 \%$ de los pobladores que presentan un capital de motilidad "medio" ostentan condición de habilidades y competencias "medio".
Por otro lado, los valores para una capacidad de agencia "alto" fluctúan entre los 18 y los 20 puntos; para "medio", entre los 15 y los 17 puntos, y para "bajo", entre los 12 y los 14 puntos, en referencia a la capacidad de actuación libre, autosuficiente, independiente, etc., respecto a la decisión de desarrollar desplazamientos.

Al respecto, el $80 \%$ de los pobladores que presentan un capital de motilidad "alto" ostentan una capacidad de agencia "media".

Observamos que el $40 \%$ de los pobladores que presentan un capital de motilidad "medio" ostentan una capacidad de agencia "baja".

En cuanto a la condición de apropiación, los valores para una condición de apropiación "alto" fluctúan entre los 24 y los 28 puntos; para "medio", entre los 19 y los 23 puntos, y para "bajo", entre los 15 y los 18 puntos, con referencia a la capacidad de uso y control del territorio.

Podemos observar que, el $60 \%$ de los pobladores que presentan un capital de motilidad "alto" ostentan una condición de apropiación "alto". Así mismo, el $60 \%$ de los pobladores que presentan un capital de motilidad "medio" ostentan una condición de apropiación "media".

En cuanto a los pobladores que ostentan un capital de motilidad "bajo", la mayoría de ellos presenta una condición de accesibilidad "baja"; condición de habilidades y competencias "baja" y "media"; capacidad de agencia "baja", y condición de apropiación "media".
(A) Tabla 1. Perfil socioeconómico, accesibilidad, competencias, agencia apropiación y capital de motilidad.

Fuente: elaboración propia (enero de 2019).

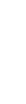


Podemos inferir, de madera general, que tener un capital de motilidad "bajo" significa que tanto la "accesibilidad" como las "competencias y las habilidades" se constituyen en obstáculos para ejercer desplazamientos. Además, no se posee capacidad de "agencia" y de "apropiación" en relación con la decisión o la autonomía para efectuar desplazamientos, $y$, por ende, se pierde capital de motilidad. Un capital de motilidad "medio" señala que se ostenta un capital constante; es decir, a pesar de que las condiciones de "accesibilidad" o de apropiación puedan ofrecer limitaciones, podemos efectuar desplazamientos en condiciones con algunas restricciones, y, por ende, no perdemos ni ganamos capital de motilidad, y un capital de motilidad "alto" refleja tanto condiciones de accesibilidad como competencias o habilidades idóneas, y así podemos decidir con total autonomía nuestros desplazamientos. Debido a nuestra alta capacidad de agencia y de apropiación, ese es un capital que posee un plusvalor.

\section{Discusión}

Tal como lo expresa García Jerez (2016), el capital de motilidad ha de estudiarse a partir de tres dimensiones: accesibilidad, competencias y habilidades; y la agencia que permite la apropiación de sus condiciones de movilidad resulta de gran utilidad para la medición de dicho capital. No obstante, el trabajo de campo permitió comprobar un mayor alcance de dichas dimensiones.

La agencia, como la capacidad de actuación en el entorno urbano inmediato, de acuerdo con los resultados obtenidos en las entrevistas, es el resultado de una sumatoria ponderada entre las condiciones de accesibilidad al entorno urbano inmediato y a las redes de movilidad urbana y las competencias o las habilidades que ostenta el individuo. Para los entrevistados, las competencias o las habilidades tienen una mayor relevancia; por lo tanto, aunque el medio urbano inmediato sea hostil o inaccesible, las competencias o las habilidades de las que goza el individuo pueden ayudarlo a sortear dichos obstáculos. Tener buena condición física y de salud, utilizar las aplicaciones para la movilidad urbana que ofrece el teléfono móvil y tener licencia de conducir, etc., pueden distinguirlos de forma comparativa y competitiva frente a otros individuos que realizan iguales desplazamientos.

Los resultados indican que las tres cuartas partes de los entrevistados utilizan el teléfono móvil para efectuar desplazamientos, y que efectúan desplazamientos a pie porque poseen mejores condiciones físicas y de salud.

A partir de esta condición fue como se estableció para el presente estudio la obligatoriedad de considerar un sumatoria ponderada, donde la agencia es producto del valor que representa las condiciones de accesibilidad más dos veces el valor que representan las habilidades o las competencias.
Respecto a eso último, el estado de la cuestión sobre las investigaciones acerca del capital de motilidad, en la actualidad, no ha sido abordado con mayor especificidad en el campo empírico; es decir, en relación con ejercicios de medición de dicho capital, la presente investigación se aproxima al desarrollo de una medición del capital de la motilidad, en un tejido social heterogéneo y microdiferenciado.

Por otra parte, los resultados más importantes nos muestran tres posibilidades. La primera es que, en primer lugar, el capital experimenta pérdida, en un primer momento, cuando sus condiciones de accesibilidad al entorno urbano inmediato y a las redes de movilidad urbana presentan obstáculos físicos y sus habilidades o competencias son limitadas. Y en segundo lugar, que cuando dichas condiciones no permiten ejercer agencia, menos aún permiten apropiarse de sus condiciones de desplazamientos, frente a un entorno urbano inmediato fragmentado socioespacialmente.

En una segunda situación posible, el capital de motilidad permanece constante; es decir, aunque el nivel de accesibilidad ofrezca limitaciones, obstáculos, estos pueden sortearse a partir de las propias competencias o habilidades. Entonces, su capital no disminuye, pero tampoco aumenta. Es un capital suficiente para enfrentar aquel territorio fragmentado socioespacialmente, pero no para efectuar mayores distancias de desplazamientos, frente a la metrópoli.

En la tercera posibilidad, el capital de motilidad aumenta ostensiblemente, debido a sus condiciones favorables de accesibilidad al entorno urbano inmediato y a sus redes de movilidad urbana. Esto define una mayor capacidad de actuación; es decir, de agencia. Por ende, la capacidad de autonomía para ejercer sus desplazamientos es mayor y de mayor potencial. Entonces se podrá enfrentar la condición de fragmentación socioespacial que el tejido urbano impone, la misma que Girón y Mansilla (2014) definen como el "urbanismo fragmentador", y recomponer la funcionalidad de este fragmento metropolitano en relación con el todo metropolitano (Martínez Toro, 2014).

Esta última situación caracteriza al individuo que ejerce lo que Bourdieu (como lo menciona García Jerez, 2016) define como "habitus ambulante", o el urbícola que democratiza el espacio público a partir del ejercicio de su ciudadanía.

\section{Conclusiones}

El capital de motilidad es una condición extrínseca al individuo: depende del nivel de consolidación del entorno urbano donde vive o trabaja, así como de las posibilidades de acceso a las redes de movilidad urbana. Pero también es una condición intrínseca a él, pues tiene relación con 
las habilidades o las competencias que el individuo posea; es decir, por ejemplo: el estado físico y de salud, el uso de las aplicaciones para la movilidad urbana de los teléfonos portátiles, el conocimiento del barrio, su propia capacidad de sociabilidad, etc.

Las mencionadas condiciones lo proveen de una capacidad de actuación o agencia sobre su medio urbano inmediato, pero, a la vez, le otorgan un nivel de apropiación; es decir, de autonomía respecto a las condiciones sobre las que puede ejercer desplazamientos reales o potenciales.

Todas estas condiciones y capacidades le confieren un capital de motilidad; es decir, la posibilidad real o potencial para desplazarse en el tiempo y el espacio, sobre un territorio determinado. En este caso, un territorio fragmentado social y espacialmente por un urbanismo fragmentador, escenario que observan las metrópolis latinoamericanas.

Este capital se pierde si el individuo experimenta dificultades de acceso al tejido urbano y a las redes de movilidad urbana donde desarrolla su vida cotidiana, si no goza de competencias o habilidades adecuadas para enfrentar un territorio fragmentado social y espacialmente, y, por lo tanto, esas condiciones no le permiten capacidad de actuación en dicho medio, y, por ende, no le permiten apropiarse de las condiciones para efectuar desplazamientos.

Por el contrario, si las condiciones de accesibilidad al entorno urbano inmediato y a las redes de movilidad urbana no reúnen las condiciones para ejercer desplazamientos, pero las habilidades o las competencias se encuentran en con- diciones óptimas, el capital de motilidad puede mantenerse constante; no pierde ni gana, pero podrá encontrar limitaciones para desplazarse fuera del entorno urbano inmediato.

No obstante lo anterior, unas condiciones adecuadas de accesibilidad al entorno urbano inmediato y a las redes de movilidad urbana, así como la presencia de habilidades o competencias en mejor estado de desarrollo, otorgarían una mayor capacidad de actuación y proveerían de un estado de apropiación con mayor autonomía que permita ejercer desplazamientos con total libertad, comodidad, seguridad, confort y rapidez. Así, el capital de motilidad se incrementa, y, por lo tanto, genera un plusvalor, se capitaliza y puede ser utilizado en cualquier momento, y así permitirle al individuo enfrentar con mayor acierto un territorio fragmentado respecto a un todo metropolitano y alcanzar la geografía de oportunidades que ofrece la metrópoli.

El presente trabajo investigativo es una primera aproximación al ejercicio de la medición del capital de motilidad de los individuos. Limitaciones en relación con la seguridad ciudadana restringieron el levantamiento de información primaria, y, de alguna manera, condicionaron las respuestas de los entrevistados; sobre todo, al tratarse de un método etnográfico del tipo microetnografía-particularista. No obstante, se constató que dicha población desarrolla estrategias de desplazamientos muy similares en las periferias de la ciudad de Lima, razón por la cual se abren enormes posibilidades para el desarrollo de líneas de investigación a propósito de este tema, con aplicaciones en el campo de la movilidad urbana sostenible, la logística urbana y la micromovilidad urbana.

\section{Referencias}

Bourdieu, P. (2012). La distinción. Criterios y bases sociales del gusto. México, DF: Tauro.

Centro Económico de Lima Norte, Municipalidad de Independencia. (2017). Análisis Foda. Recuperado de:

https://es.scribd.com/document/349623686/ Analisis-Foda-Independencia

Flamm, M. \& Kaufmann, V. (2006). Operationalising the concept of motility: A qualitative study. Journal Mobilities, 1(2), 167-189. https://doi.org/10.1080/17450100600726563

García Jerez, F. A. (2016). ¿En bus o en carro? Capital de motilidad, clases medias y nuevos barrios en una ciudad colombiana. Revista Transporte y Territorio, (15), 348368. Recuperado de

http://revistascientificas.filo.uba.ar/index. php/rtt/article/view/2864/2487

Hernández Sampieri, R., Fernández Collado, C., \& Baptista Lucio, P. (2014). Metodología de la investigación. (6 ed.). Barcelona, spaña: Editorial McGraw-Hill Education.

Instituto Nacional de Estadística e Informática (INEI). (2009). Mapa de desnutrición crónica en niñas y niños menores de cinco años a nivel provincial y distrital. Recuperado de: http://www2.congreso.gob.pe/sicr/cendocbib/con4 uibd.nsf/915B4499240864A405257B82007270FF/\%24FILE/Mapa de Desnutricion_2009.pdf
Instituto Nacional de Estadística e Informática (INEI). (2016). Planos estratificados de Lima Metropolitana a nivel de manzana según ingreso per cápita del hogar y según grupos de pobreza monetaria. p. 27.

Instituto Nacional de Estadística e Informática (INEI). (2017). Provincia de Lima. Compendio 2017. Recuperado de:

https://www.inei.gob.pe/media/MenuRecursivo/ publicaciones_digitales/Est/Lib1477/libro.pdf

Jirón, P. \& Mansilla, P. (2014). Las consecuencias del urbanismo fragmentador en la vida cotidiana de habitantes de la ciudad de Santiago de Chile. Revista EURE, 40 (112), 5-28. Recuperado de: http://repositorio.uchile.cl/ handle/2250/130629

Kaufmann, V., Bergman, M., \& Joye, D. (2004). Motility: Mobility as capital. International Journal of urban and Regional Research, 28(4), 745-756.

https://doi.org/10.1111/j.0309-1317.2004.00549.x

Martínez Toro, Pedro Martín (2015). La producción del espacio en la ciudad latinoamericana. El modelo del impacto del capitalismo global en la metropolización. Hallazgos, 12(23),211-229. Recuperado de http://www.scielo.org.co/pdf/hall/v12n23/ v12n23a11.pd
Mejía Navarrete, J. (2011). Problemas centrales del análisis de datos cualitativos. Revista Latinoamericana de metodología de la Investigación Social, 1(1), 47-60. Recuperado de:

http://jbposgrado.org/icuali/An\%E1lisis\%20 d e \% 20 dat os $\% 20$ cualitativos \% 20 problemas\%20centrales.pdf

Quispe, R., Sarmiento, H., Solis, C., \& Sotelo, F. (2017). Planeamiento Estratégico del Distrito de Independencia de la Ciudad de Lima (tesis para obtener el grado de Magíster en Administración de Empresas otorgado por la Pontificia Universidad Católica del Perú). Recuperadode

http://tesis.pucp.edu.pe/repositorio/ bitstream/handle/20.500.12404/9854/ Q U I S P E S A R M I E N T O PLANEAMIENTO INDEPENDENCIA. pdf? sequence $=1 \& \overline{\text { isAllowed }}=y$

Vignoli Rodríguez, J. (2008). Movilidad cotidiana, desigualdad social y segregación residencial en cuatro metrópolis de América Latina. EURE, 103(34), 49-71. http://dx.doi.org/10.4067/S025071612008000300003 


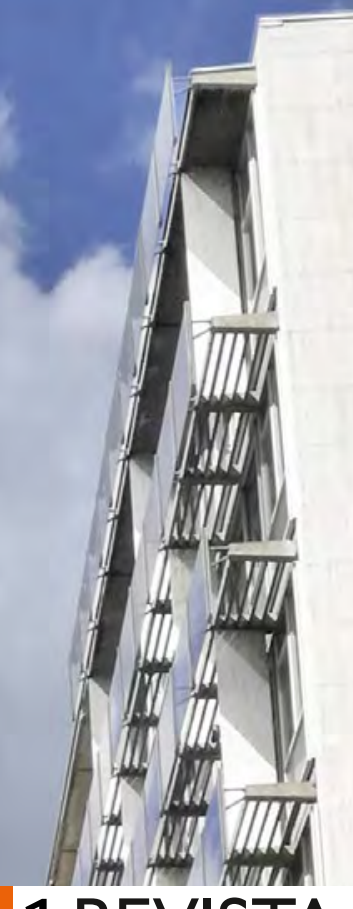

\section{Nro. 1 REVISTA DE ARQUITECTURA}
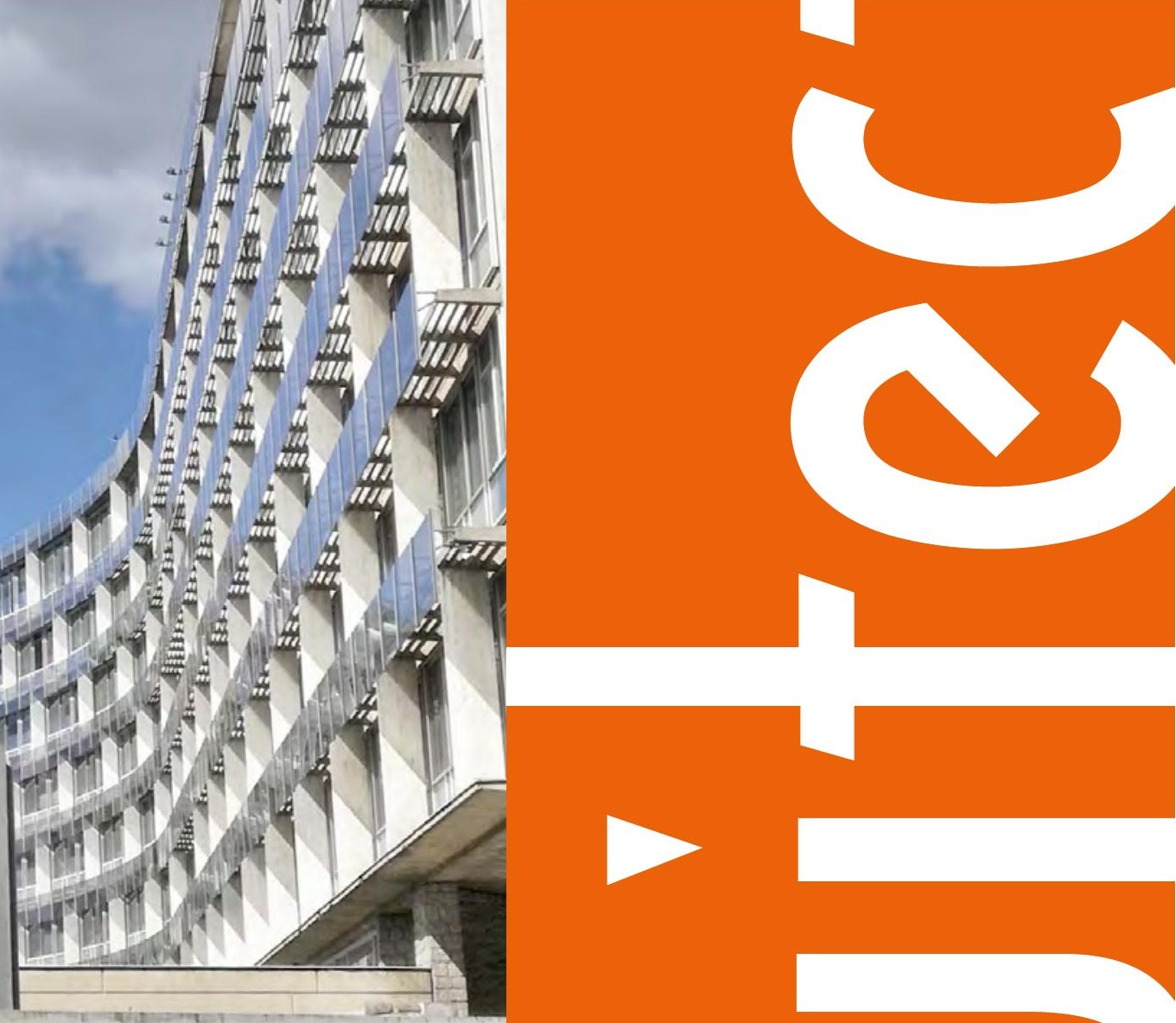

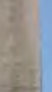

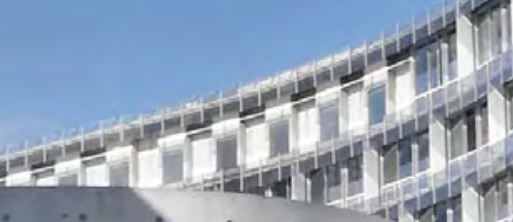

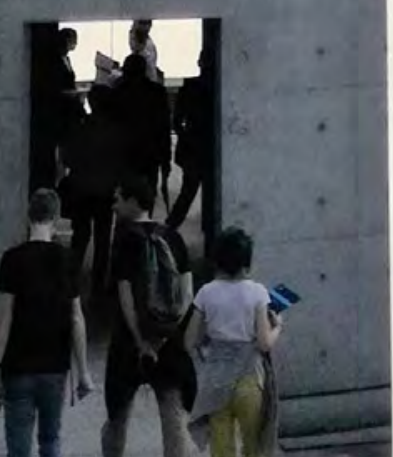

$\Phi$

- Revista de Arquitectura (Bogotá)

- Vol. 22 Nro. 12020 enero-junio

•pp. 1-188•ISSN: 1657-0308•E-ISSN: 2357-626X

- Bogotá, Colombia
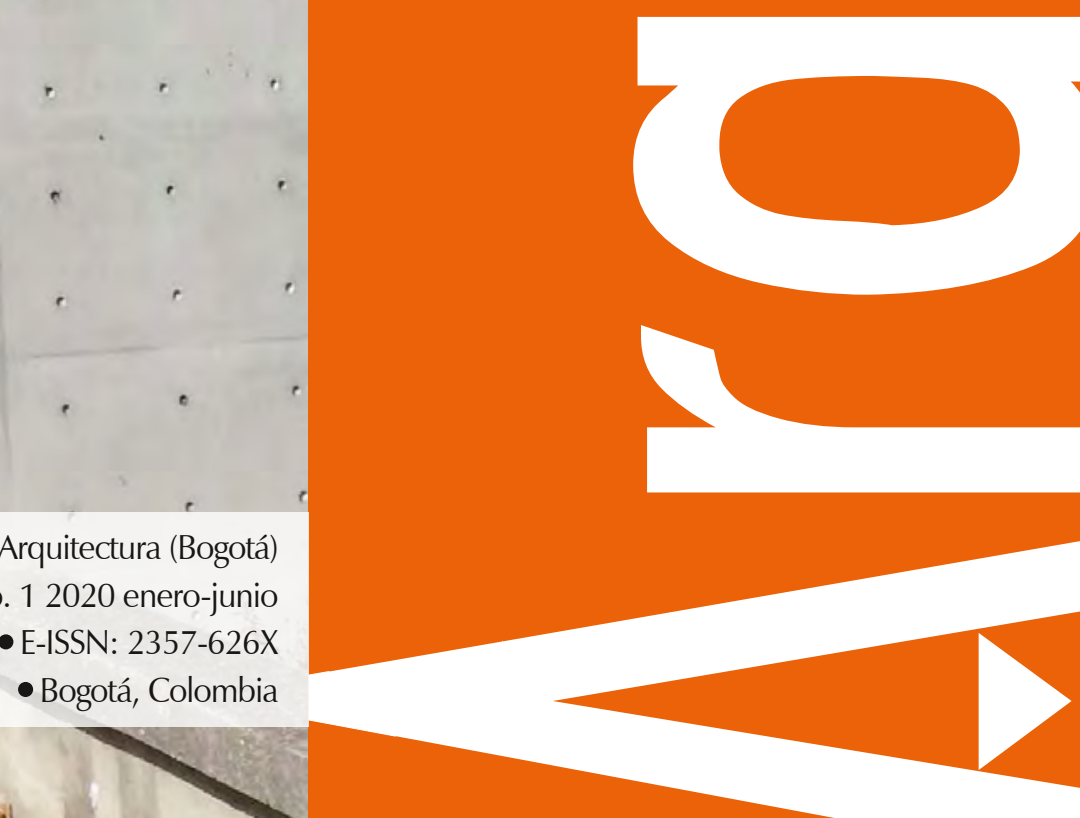


\section{Enfoque y alcance}

La Revista de Arquitectura (Bogotá) ( (ISSN 1657-0308 Impresa y E-ISSN 2357-626X en línea) es una publicación científica seriada de acceso abierto, arbitrada mediante revisión por pares (doble ciego) e indexada, en donde se publican resultados de investigación originales e inéditos.

Está dirigida a la comunidad académica y profesional de las áreas afines a la disciplina. Es editada por la Facultad de Diseño y el Centro de Investigaciones (CIFAR) de la Universidad Católica de Colombia en Bogotá (Colombia).

La principal área científica a la que se adscribe la Revisto de Arquitectura (Bogotá) según la OCDE es:

Gran área: 6. Humanidades

Área: 6.D. Arte

Disciplina: 6D07. Arquitectura y Urbanismo

También se publican artículos de las disciplinas como 2A02, Ingeniería arquitectónica; 5C03, Estudios urbanos (planificación y desarrollo); 6D07, Diseño.

Los objetivos de la Revista de Arquitectura (Bogotá) son:

- Promover la divulgación y difusión del conocimiento generado a nivel local, nacional e internacional

- Conformar un espacio para la construcción de comunidades académicas y la discusión en torno a las secciones definidas.

- Fomentar la diversidad institucional y geográfica de los autores que participan en la publicación.

- Potenciar la discusión de experiencias e intercambios científicos entre investigadores y profesionales.

- Contribuir a la visión integral de la arquitectura, por medio de la concurrencia y articulación de las secciones mediante la publicación de artículos de calidad.

- Publicar artículos originales e inéditos que han pasado por revisión de pares, para asegurar que se cumplen las normas éticas, de calidad, validez científica, editorial e investigativa.

- Fomentar la divulgación de las investigaciones y actividades desarrolladas en la Universidad Católica de Colombia.
Palabras clave de la Revista de Arquitectura (Bogotá): arquitectura, diseño, educación arquitectónica, proyecto y construcción, urbanismo.

Idiomas de publicación: español, inglés, portugués y francés. Título abreviado: Rev. Arquit.

\section{Titulo corto: RevArq}

\section{Políticas de sección}

La revista se estructura en tres secciones correspondientes a las líneas de investigación activas y aprobadas por la institución, y dos complementarias, que presentan dinámicas propias de la Facultad de Diseño y las publicaciones relacionadas con la disciplina.

Cultura y espacio urbano. En esta sección se publican los artículos que se refieren a fenómenos sociales en relación con el espacio urbano, atendiendo aspectos de la historia, el patrimonio cultural y físico, y la estructura formal de las ciudades y el territorio.

Proyecto arquitectónico y urbano. En esta sección se presentan artículos sobre el concepto de proyecto, entendido como elemento que define y orienta las condiciones proyectuales que devienen en los hechos arquitectónicos o urbanos, y la forma como estos se convierten en un proceso de investigación y nuevo de conocimiento. También se presentan proyectos que sean resultados de investigación, los cuales se validan por medio de la ejecución y transformación en obra construida del proceso investigativo. También se contempla la publicación de investigaciones relacionadas con la pedagogía y didáctica de la arquitectura, el urbanismo y el diseño.

Tecnología, medioambiente y sostenibilidad. En esta sección se presentan artículos acerca de sistemas estructurales, materiales y procesos constructivos, medioambiente y gestión, relacionados con los entornos social-cultural, ecológico y económico.

Desde la Facultad. En esta sección se publican artículos generados en la Facultad de Diseño, relacionados con las actividades de docencia, extensión, formación en investigación o internacionalización, las cuales son reflejo de la dinámica y de las actividades realizadas por docentes, estudiantes y egresados; esta sección no puede superar el $20 \%$ del contenido.

Textos. En esta sección se publican reseñas, traducciones y memorias de eventos relacionados con las publicaciones en Arquitectura y Urbanismo.
A Frecuencia de publicación

Desde 1999 y hasta el 2015, la Revista de Arquitectura (Bogotá) publicó un volumen al año, a partir del 2016 se publicarán dos números por año en periodo anticipado, enero-junio y julio-diciembre, pero también maneja la publicación anticipada en línea de los artículos aceptados (versión Post-print del autor).

La Revista de Arquitectura (Bogotá) se divulga mediante versiones digitales (PDF, HTML, EPUB, XML) e impresascon un tiraje de 700 ejemplares, los tiempos de producción de estas versiones dependerán de los cronogramas establecidos por la editorial.

Los tiempos de recepción-revisión-aceptación pueden tardar entre seis y doce meses dependiendo del flujo editorial de cada sección y del proceso de revisión y edición adelantado.

Con el usuario y contraseña asignados, los autores pueden ingresar a la plataforma de gestión editorial y verificar el estado de revisión, edición o publicación del artículo.
A Canje

La Revista de Arquitectura (Bogotá) está interesada en establecer canje con publicaciones académicas, profesionales o científicas del área de Arquitectura y Urbanismo, como medio de reconocimiento y discusión de la producción científica en el campo de acción de la publicación.

\section{Mecanismo}

Para establecer canje por favor descargar, diligenciar y enviar el formato: RevArq FP20 Canjes
Universidad Católica de Colombia (2020, enero-junio). Revista de Arquitectura (Bogotá), 22(I) I-188. Doi: 10.14718

ISSN: 1657-0308 E-ISSN: 2357-626X

Especificaciones:

Formato: $34 \times 24 \mathrm{~cm}$

Papel: Mate $115 \mathrm{~g}$

Tintas: Negro y policromía
A Contacto

Dirección postal:

Avenida Caracas No. 46-72.

Universidad Católica de Colombia

Bogotá D.C.(Colombia)

Código postal: 111311

Facultad de Diseño Centro de Investigaciones (CIFAR). Sede El Claustro. Bloque " $\mathrm{L}$ ", 4 piso Diag. 46A No. $15 \mathrm{~b}-10$ Editor, Arq. César Eligio-Triana

Teléfonos:

+57 (1) $3277300-3277333$

Ext. 3109; 3112 o 5146

Fax: +57 (1) 2858895
Correo electrónico: revistadearquitectura@ucatolica.edu.co cifar@ucatolica.edu.co

Página WEB: www.ucatolica.edu.co vínculo Revistas científicas

http://publicaciones.ucatolica.edu.co revistas-cientificas http://editorial.ucatolica.edu.co/ojsucatolica/revistas ucatolica/index.php/RevArq 
